\title{
Neural rhythmic symphony of human walking observation: Upside-down and Uncoordinated condition on cortical theta, alpha, beta and gamma oscillations
}

\author{
David Zarka ${ }^{1}$, Carlos Cevallos ${ }^{1}$, Mathieu Petieau ${ }^{1}$, Thomas Hoellinger ${ }^{1}$, Bernard Dan ${ }^{1,2}$ and \\ Guy Cheron ${ }^{1,3 *}$
}

' Laboratory of Neurophysiology and Movement Biomechanics, Université Libre de Bruxelles, Brussels, Belgium

${ }^{2}$ Department of Neurology, Hopital Universitaire des Enfants reine Fabiola, Université Libre de Bruxelles, Bruxelles, Belgium

${ }^{3}$ Laboratory of Electrophysiology, Université de Mons-Hainaut, Bruxelles, Belgium

\section{Edited by:}

Mikhail Lebedev, Duke University, USA

\section{Reviewed by:}

Daniel P. Ferris, University of

Michigan, USA

Lewis A. Wheaton, Georgia Tech, USA

Miguel Escudero, University of Seville, Spain

*Correspondence:

Guy Cheron, Laboratory of Neurophysiology and Movement Biomechanics, Université Libre de Bruxelles, CP 640, $50 \mathrm{Av}$. F.

Roosevelt, 1050 Brussels, Belgium e-mail:gcheron@ulb.ac.be
Biological motion observation has been recognized to produce dynamic change in sensorimotor activation according to the observed kinematics. Physical plausibility of the spatial-kinematic relationship of human movement may play a major role in the top-down processing of human motion recognition. Here, we investigated the time course of scalp activation during observation of human gait in order to extract and use it on future integrated brain-computer interface using virtual reality (VR). We analyzed event related potentials (ERP), the event related spectral perturbation (ERSP) and the inter-trial coherence (ITC) from high-density EEG recording during video display onset $(-200-600 \mathrm{~ms})$ and the steady state visual evoked potentials (SSVEP) inside the video of human walking 3D-animation in three conditions: Normal; Upside-down (inverted images); and Uncoordinated (pseudo-randomly mixed images). We found that early visual evoked response P120 was decreased in Upside-down condition. The N170 and P300b amplitudes were decreased in Uncoordinated condition. In Upside-down and Uncoordinated conditions, we found decreased alpha power and theta phase-locking. As regards gamma oscillation, power was increased during the Upside-down animation and decreased during the Uncoordinated animation. An SSVEP-like response oscillating at about $10 \mathrm{~Hz}$ was also described showing that the oscillating pattern is enhanced $300 \mathrm{~ms}$ after the heel strike event only in the Normal but not in the Upside-down condition. Our results are consistent with most of previous point-light display studies, further supporting possible use of virtual reality for neurofeedback applications.

\section{Keywords: ERP, ERSP, ITC, SSVEP, walking, observation, virtual reality}

\section{INTRODUCTION}

Neuronal processing of the visual system allows us to perceive objects, movements, colors, contrasts, and to represent the space around us with a very high resolution. In addition to the classical dichotomy between the ventral stream (the "What" pathway) supporting object vision and a dorsal stream (the "Where" pathway), a more recent conception based on clinical evidence (Kravitz et al., 2011) divides the dorsal stream into three sub-pathways projecting on to the premotor (supporting visually-guided actions), the prefrontal and the medial temporal lobes (supporting spatial working memory) both directly and through the posterior cingulate and retrosplenial areas (supporting navigation). This emphasizes the contribution of numerous functionally specialized, hierarchically organized visual areas giving rise to a conscious perception of the different attributes of the visual scene (Zeki et al., 1991; Singer, 1999). The discovery of the phase-locking mechanism at the level of the cortical neurons producing gamma oscillation (Gray et al., 1989) constitutes a strong scientific foundation for the binding by synchrony hypothesis (Singer, 1999) and has also paved the way for noninvasive investigation of the implicated mechanisms by electroencephalography (EEG) and event-related potentials (ERP) (Makeig et al., 2002; Cheron et al., 2007, 2014; Cebolla et al., 2009, 2014). New approaches of signal analysis (Delorme and Makeig, 2004) have permitted to better understand the genesis of the sensory evoked responses including visual motion in VR environment (Gramann et al., 2009; Cheron et al., 2014) and the origin of the movement gating of sensory evoked responses (Cebolla et al., 2009).

The discovery of mirror neurons responding similarly when the monkey performs an action and when it observes the experimenter performing the same action (Rizzolatti et al., 1996) has led to human studies of visual processes involved in recognition (Blake and Shiffrar, 2007; Avanzini et al., 2013; Di Dio et al., 2013), prediction of others' movements (Csibra, 2007; Kilner et al., 2007), and their implication in social cognition (Jacob and Jeannerod, 2005; Schütz-Bosbach and Prinz, 2007; Heyes, 2010; Press et al., 2011). Behavioral, neuroimaging and 
neurophysiological data have demonstrated a high sensitivity to reference frame (Pavlova and Sokolov, 2000; Pavlova et al., 2004; McGlothlin et al., 2012), human body form (Downing et al., 2001), kinematics of human movement (Avanzini et al., 2012; McAleer et al., 2014), gender and personal traits (Pollick et al., 2005; Troje et al., 2005; McGlothlin et al., 2012). Several studies demonstrated that shape and motion information are treated separately by ventral and dorsal visual streams, and converge to the posterior portion of superior temporal sulcus (Vaina et al., 2001; Giese and Poggio, 2003; Blake and Shiffrar, 2007). Moreover, the motor theory of perception, based on the fact that movement perception is influenced by the implicit knowledge about the working principles of the motor control system (Viviani and Stucchi, 1992; Rizzolatti and Craighero, 2004), give a critical place to ventral premotor cortex in biological motion perception processes (Saygin et al., 2004).

By extending Darwin's evolutionary perspective about face emotion (Darwin, 1872) to human locomotion, we may advance that the recognition of the human primate by its bipedal locomotion already present in early hominid before stone tools and large brains (Leakey and Walker, 1997) is probably one of the most vital activities of human in a selection retrospective view. Moreover, such human gestures may represent a constitutive element of the emotional body language (De Gelder, 2006, for a review). This whole body movement of homo sapiens is characterized by distinctive patterns of smooth, regular, alternated lower and upper limbs movements performed around a relatively fixed and erected posture of the head and trunk segment (Pozzo et al., 1990). Another remarkable element is the heelstrike considered as an acquired character of African and Asian apes linked closely to knuckle walking quadrupedalism (Thorpe et al., 2007; Crompton et al., 2010). These highly recognizable elements would implicate that human mirror neuron systems should be active when watching somebody else walk (Cheng et al., 2005).

Thanks to dynamics analysis of high-density EEG associating event-related potential (ERP), event-related spectral perturbation (ERSP) and inter-trial coherency (ITC), it has become possible to identify electrophysiological mechanisms related to recognition processes (Engel et al., 1997; Singer, 2009). In this context, coherent stimulus representation, including biological motion (Pavlova et al., 2004), are thought to result from binding of widely distributed cell ensembles by synchronizing their high-frequency oscillation activity (Tallon-Baudry and Bertrand, 1999; Singer, 2009). In parallel, other oscillatory processes may be activated following a motor template as suggested for mu rhythm (Ulloa and Pineda, 2007; Arnstein et al., 2011; Braadbaart et al., 2013; Urgen et al., 2013; Frenkel-Toledo et al., 2014). Point-light display of human locomotion has been used to characterized the cortical activity involved in recognition of locomotion either through MEG (Pavlova et al., 2004, 2006) or ERP studies (Hirai et al., 2003, 2005, 2013; Jokisch et al., 2005; Hirai and Hiraki, 2006; Krakowski et al., 2011; Buzzell et al., 2013).

Here, we studied the ERP and dynamics of theta, alpha, beta and gamma oscillations induced by the observation of an animated avatar in a virtual reality (VR). We hypothesized that physical plausibility of the spatial-kinematic of human locomotion plays a major role in different modes of neural processing (bottom-up and top-down) implicated in locomotion recognition: we expect that these processes will be reflected in different contributions of rhythmic power and phase-locked perturbation in different frequency bands and cortical areas. To address this question, we used an animation representing a human mannequin during walking action performed in normal, Uncoordinated kinematics and in Upside-down views. This will offer the possibility to extract the dynamic signature of human walking observation with respect to the neural activity evoked by the same image content but in an unusual frame of reference (Upside-down view) or without respect to normal kinematics (Uncoordinated walk) from the EEG signals.

\section{MATERIALS AND METHODS ARTICIPANTS}

Sixteen healthy volunteers took part in this study (ten males, mean age 25.9 years, range 18-35 years). All subjects were righthanded, had Normal or corrected-to-Normal vision, were naive with respect to the purpose of the experiment, and gave informed consent. The experiment was performed with the approval of the ethics committee of Université Libre de Bruxelles and realized in accordance with the ethical standards of the 1964 Declaration of Helsinki.

\section{STIMULI}

Visual stimuli consisted of an animation in the center of the screen representing human walking mannequin (from Cal3D Library) that was presented in three different ways: Normal walk$\operatorname{ing}(\mathrm{N})$, Upside-down (U), and Uncoordinated (J) (Figure 1). Each animation was organized in 22 blocks of $10 \mathrm{~s}$ duration interspersed by 7-12s of random periods of gray screen. This allowed us to obtain a repetitive control of the baseline state throughout the whole recording session and facilitated the recording of the averaged responses (see below). For the Normal walking condition, each block was initiated by an image representing the heel strike event of the right leg and was ended by the last image preceding the next heels strike of the right leg picture (Figure 1A). The animation had a $10 \mathrm{~Hz}$ frequency. In the Upside-down condition the same successive pictures were merely inverted, keeping the same kinematics sequences. In the Uncoordinated condition the first image remained the same as the Normal condition while all the others were randomly mixed giving rise to an incoherent Uncoordinated movement. The random sequence was conserved for each trial and each subject (Figure 1B).

We have calculated the luminosity of each image in the three colors (RGB) by using "imread" MATLab function. This function stores in a matrix the composition in red, green and blue of each pixel of an image. For each frame of the animation, we subtracted this matrix to that of the previous frame. We have then computed the mean of the resulting matrix and called this composition "dynamic contrast." This represents overall change between two successive frames of the composition in luminosity of the same located pixels. 


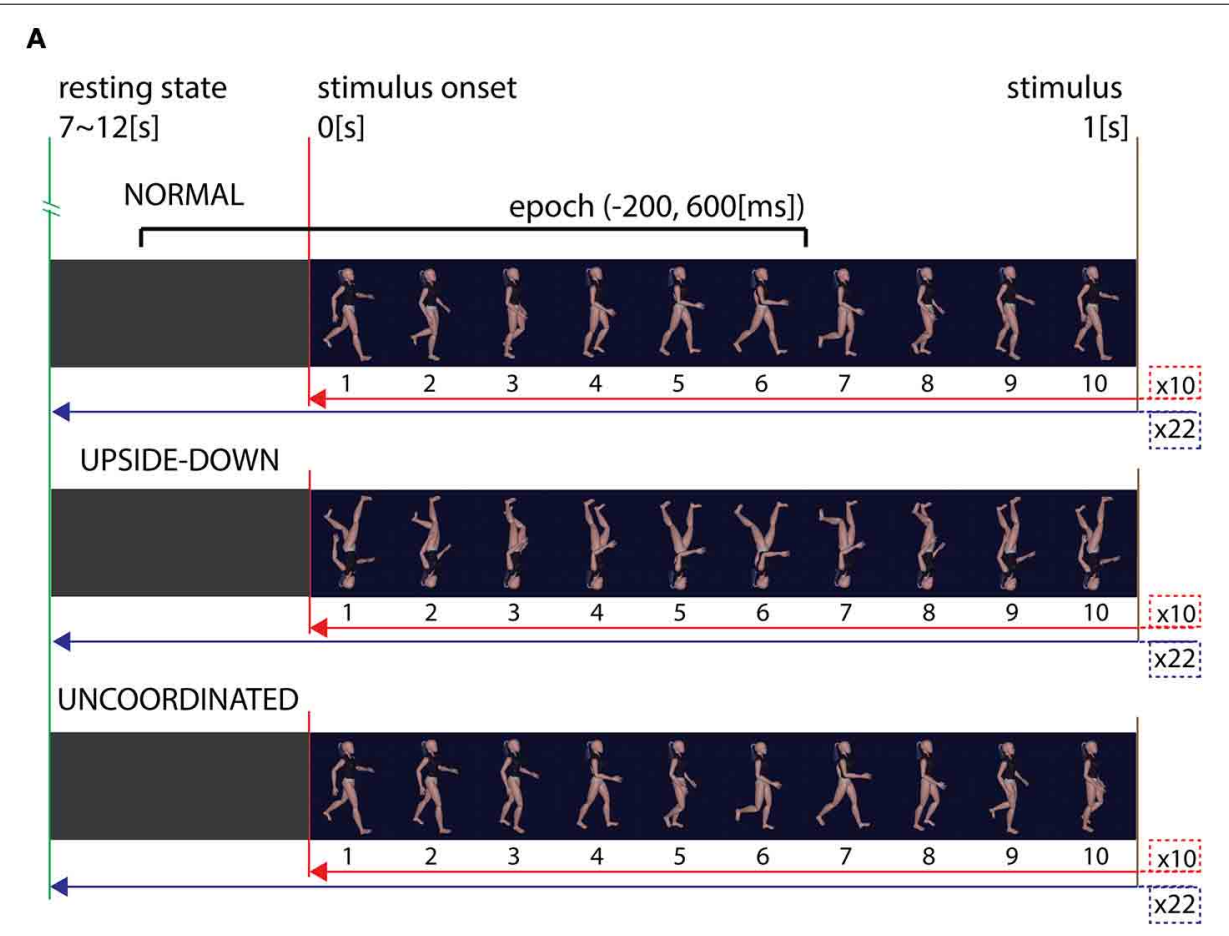

B

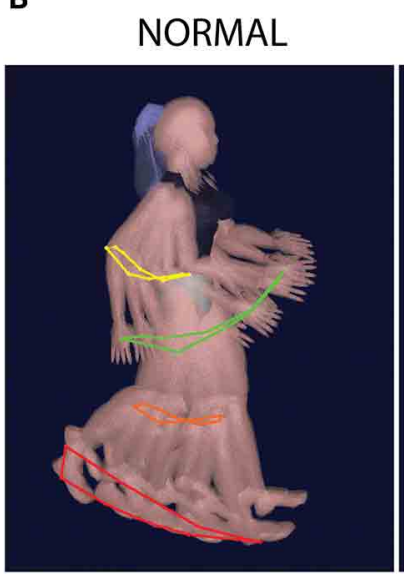

UPSIDE DOWN

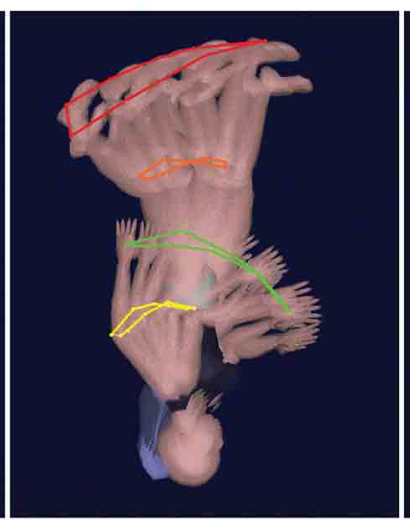

UNCOORDINATED

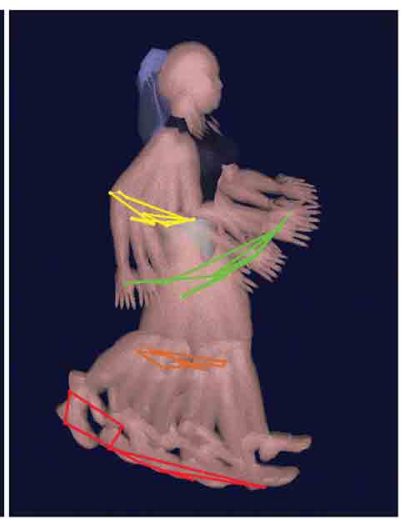

FIGURE 1 | Condition's stimuli. (A) Time representation of the stimuli in each three conditions. Normal condition shows ten successive gait cycles of $1 \mathrm{~s}$ each. Trials were separated by 7-12 s of gray screen and repeated 22 times. Upside-down condition show the same images sequence, rotated to $180^{\circ}$ in the image plane. Uncoordinated condition show the same first image as the Normal condition while all the others images were mixed. (B) Kinematics representation of the gait in the three conditions. While Normal and Upside-down conditions have the same coherent kinematic sequence, Uncoordinated condition show an incoherent kinematic sequence.

\section{EXPERIMENTAL SETUP}

The recording was realized in a single session. EEG was recorded in 128 channels (ANT system, The Netherlands) at a sampling frequency of $2048 \mathrm{~Hz}$ and with a resolution of 22 bits (71.5 $\mathrm{nV}$ per bit). An active-shield cap using $128 \mathrm{Ag} / \mathrm{AgCl}$ sintered ring electrodes and shielded co-axial cables (5-10 electrode system placements) was comfortably adjusted to subject head. All electrodes were referred to left earlobe. Impedance was lowered below $10 \mathrm{k} \Omega$ for each electrode and checked before each recording. Displays were presented on a $17^{\prime \prime}$ Dell computer screen. Participants looked straight ahead at the computer screen through a form-fitting facemask and a circular barrel (cylinder). The screen was centered on the line of gaze at a distance of $\sim 30 \mathrm{~cm}$ from the eyes. Viewing through the barrel removed any external visual references. In addition, subjects had earplugs to isolate from external hearing disturbance. For eight subjects, we presented in three successive sessions the Normal walking condition, then Upside-down walking and then Uncoordinated one (No-Random group). For eight other subjects, conditions were presented randomly in three successive sessions (Random group). We made a pause between each session in order to limit the effect of fatigue. As the aim of this study was to evaluate the effect of 
purposeless perception on the brain rhythms, no particular attentional task was required. However, the state of awareness was continuously checked by online EEG (absence of slow rhythm linked to drowsiness) and EOG, for which we placed electrodes above, below, right and left of the right eye. In particular, we checked that the blink number and configuration remained unchanged throughout the experimental session. We used an in-house script that counts the number of blinks by incrementing an index for each potential higher than $250 \mu \mathrm{V}$, and calculates the interval between blinks to provide a view of their configuration over time. We then calculated the number of saccades by EOG derived function. The results show there is no difference between conditions for blink (means by subject for Normal: $81 \pm 33.3$; Upside-down: $99.8 \pm 27.2$; Uncoordinated: $120.4 \pm 34.6$ ) and saccades (means by subject for Normal: $316 \pm 137.8$; Upside-down: $455.4 \pm 98.3$; Uncoordinated: $385.2 \pm 136.6$ ).

\section{DATA TREATMENT}

Off-line data treatment and analysis was performed by means of EEGLAB software (Delorme and Makeig, 2004; Brunner et al., 2013) and in-house MATLAB-based tools (Cheron et al., 2014). DC offset was removed, then band pass filter $0.1-80 \mathrm{~Hz}$ and notch filter around $50 \mathrm{~Hz}(47.5-52.5 \mathrm{~Hz})$ were applied to attenuate electrical artifacts. Portions of data and defective electrodes (max. $6 \%$ ) were removed by careful visual inspection. Ocular (blink and saccade) and any other remaining artifacts (muscular, cardiac) were isolated by ICA algorithm decomposition. We used the scalp topography, temporal activity localization and spectra magnitude criterion to identify ICA related to artifact. In case of doubt the rejection occurred only if all experimenters involved in data treatment reached agreement. After ICA rejection, defective electrodes were spherically interpolated.

Two analyses were performed: animation onset analysis and SSVEP analysis. In the animation onset analysis, data were organized in epochs corresponding to intervals $[-1000 ; 3000] \mathrm{ms}$, centered on animation onset. We rejected epochs according to $\pm 100 \mu \mathrm{V}$ threshold criterion, and we made a visual review to confirm epoch rejection. In total, we obtained $17 \pm 5$ epochs per subject $(n=16)$ and per condition $(n=3)$. A study design was used to average data from subjects for each condition. A time window of $1000 \mathrm{~ms}$ before stimulus onset was used as baseline.

In SSVEP analysis, data were organized in epochs corresponding to intervals $[-200 ; 600] \mathrm{ms}$, centered on each heel strike except for the first and the last one. As in preceding analysis, we applied $\pm 100 \mu \mathrm{V}$ threshold criterion confirmed by a visual review. In total, we obtained $159 \pm 16)$ epochs per subject $(n=16)$ and per condition $(n=3)$. We performed a grand average study including $2065 \pm 26$ trials for each condition. The interval $[-200 ; 0] \mathrm{ms}$ was used as baseline, and the first and last heel strikes were excluded from the analysis In this case, the SSVEP analysis was independent of the neutral black screen periods allowing to join mixed Random and Non-Random groups.

A subset of 32 electrodes was explored for each measure analysis: O2, Oz, O1, POz, P8, P4, Pz, P3, P7, CP6, CP2, CP1, CP5, T8, C4, Cz, C3, T7, FC6, FC2, FC1, FC5, F8, F4, Fz, F3, F7, Fp2,
Fpz, Fp1. We first checked ERP and ERSP of [-1000; 3000] ms epoch, and then we focused on events related to animation onset, and SSVEP centered on heel strike between -200 and $600 \mathrm{~ms}$. ERP, ERSP, and ITC analysis was performed. Difference between Random and No-Random groups and between Normal and both Upside-down and Uncoordinated condition were performed by EEGLab non-parametric permutation test $(n=2000)$ at each trial latency of the average ERPs and every time-frequency point for ERSP and ITC.

\section{RESULTS \\ EVENT-RELATED POTENTIAL}

The first noticeable ERP component referenced to the earlobe elicited after the onset of the VR-animation was the P120 component recorded in occipito-parietal electrodes. Analysis revealed a peak reduction in Upside-down condition with respect to Normal condition over occipito-parietal regions. The next component was the N170 mainly recorded over the occipito-parietal regions (Figure 2). We observed a significant decrease in Uncoordinated condition over occipital and parieto-lateral regions. This was followed by a large P300 component ending at about $500 \mathrm{~ms}$ in occipital regions and $400 \mathrm{~ms}$ in frontal regions. In order to simplify the description of condition effect, we subdivided P300 in the two classical P300a and P300b components (Figure 2). The P300a component was significantly smaller in the Upside-down condition over parietal regions with respect to the Normal situation, whereas the P300b component remained the same. On the contrary in the Uncoordinated condition, the P300a component was not modified whereas the P300b showed a significant decrease in occipital and parietal regions (Table 1). Comparison between Random and No-Random group revealed no significant difference between their respective conditions except in the P300 amplitude in parietal region which was greater for the No-Random group for the 3 conditions.

\section{EVENT-RELATED SPECTRAL PERTURBATION AND INTER-TRIAL COHERENCE}

Whatever the observed condition (Figures 3-5), the video onset triggered throughout the scalp a theta ERS in the $[0 ; 500] \mathrm{ms}$ interval followed by an alpha ERD initiated at about $200 \mathrm{~ms}$ and maintained during all the duration of the video. This alpha ERD was accompanied by a beta ERD which was more pronounced in the Uncoordinated condition (Figure 5). The Normal presentation induced a gamma ERD at about $700 \mathrm{~ms}$ and maintained for all the duration of the video in the left sensori-motor region (Figure 3, CP5 electrode). This gamma ERD was not present in the two others conditions (Figures 4, 5).

In the $[-200 ; 600]$ ms time-window, the Normal condition was characterized by the following observations (Figures 6-9): (1) at the latency of the P120, ERSP plots showed an earlier alpha ERS reaching maximal value in the parietal region and extending to the beta band in the parieto-central region. (2) This was sustained by theta activation and phase-locking presenting its maximal value at about $200 \mathrm{~ms}$. (3) ERD in the upper alpha band at about $200 \mathrm{~ms}$ in the occipito-parietal regions. (4) ERS clusters in the gamma range $(30-70 \mathrm{~Hz})$ in the parieto-occipital and centro-frontal regions. 


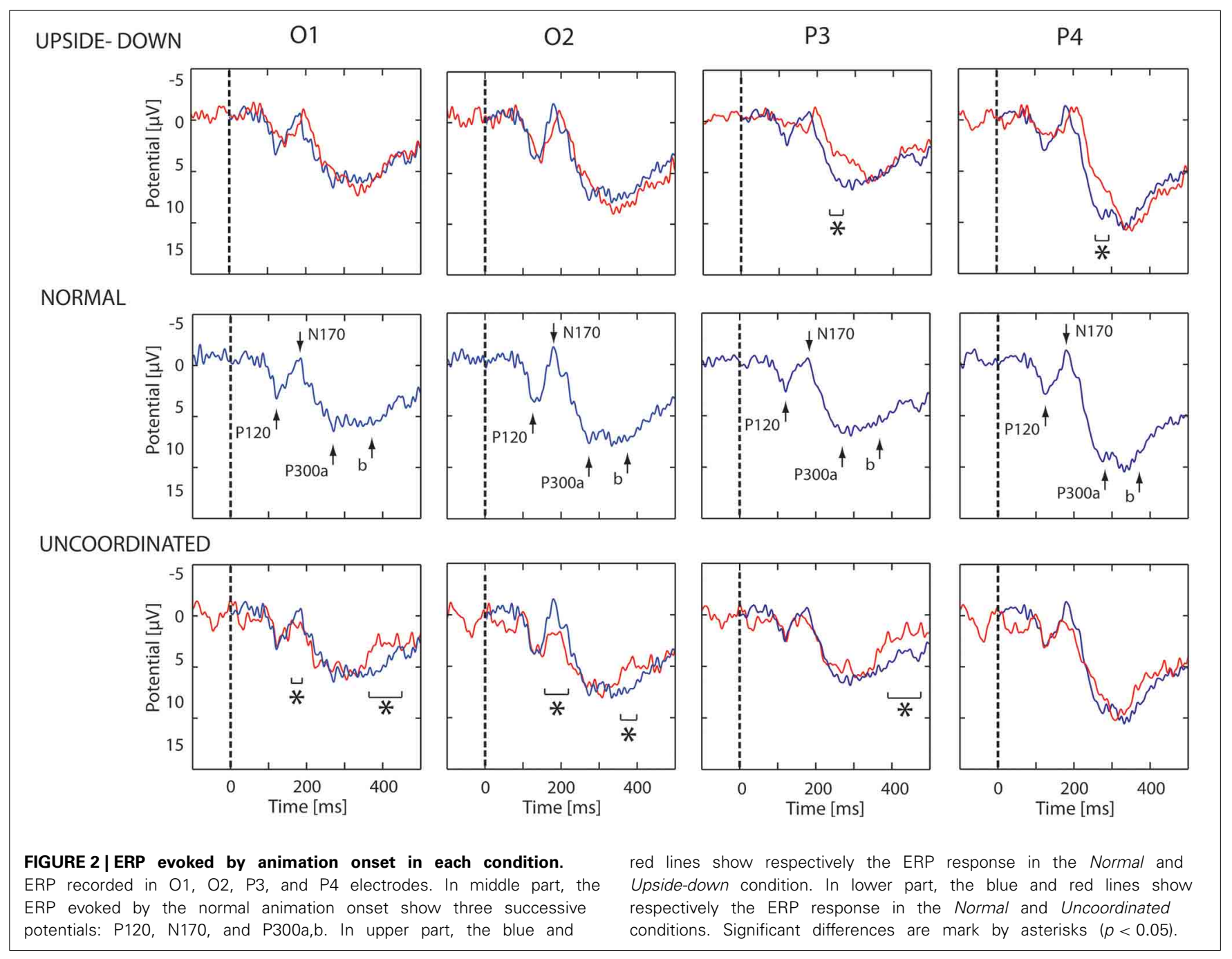

With respect to the Normal condition, in the Upside-down condition, three significant changes were noted (Figures 6-9): (1) a decrease in alpha-beta power between 100 and $500 \mathrm{~ms}$ over occipital to frontal regions, resulting in a lack of ERS in alpha bands at the latency of the P120, and an increased alpha-beta ERD at about 200-500 ms; (2) a decrease of the theta phase-locking in the parieto-central regions; (3) an increase in (gamma) 40 and $60 \mathrm{~Hz}$ ERS over occipito-central regions, respectively at about 150 and 350 ms latency (Table 1).

With respect to the Normal condition, in the Uncoordinated condition the following was observed (Figures 6-9): (1) a decrease of alpha-beta band at the latency of the P120, followed by an earlier and greater alpha-beta ERD over the occipitoparietal region; (2) a reduction of theta phase-locking. However, in contrast to the Upside-down and Normal condition, (3) the Uncoordinated animation produced a gamma $40-60 \mathrm{~Hz}$ ERD at about $200-500 \mathrm{~ms}$ over occipito-central regions (Table 1). The analysis of the dynamic contrast of the image showed that the Uncoordinated condition presented an increased contrast between the third and the fourth image ( $400 \mathrm{~ms}$ after the onset) with respect to the two other conditions.

\section{STEADY STATE VISUAL EVOKED POTENTIALS}

When the heel strike of the right leg was used as trigger, the average trace corresponded to an oscillatory pattern peaking at about $9 \mathrm{~Hz} .(8.86 \mathrm{~Hz})$. This was observed for all subjects and conditions and may be considered as a SSVEP induced by the frequency of the video. Figure 10 illustrates the SSVEP traces resulting from a grand average of all the 16 subjects which conserve the $9 \mathrm{~Hz}$ oscillating pattern presented in each single subject. However, the amplitude of the grand average oscillation was not constant throughout the time period. The first negative peak occurred close to $100 \mathrm{~ms}$ after the heel strike in any of the 3 different conditions (Figure 10A). For Normal and Upside-Down condition the SSVEP amplitude increased after the heel strike and culminated at a latency of $300 \mathrm{~ms}$ (negative peak) only in the Normal condition. Thereafter, the oscillating pattern decreased in Normal and Upside-down condition but was maintained in the Uncoordinated condition.

The Upside-down condition showed a significant decrease of the third negative SSVEP component at $300 \mathrm{~ms}$ with respect to the Normal condition over parieto-occipital regions (Figure 10A, 
Table 1 | Summary of statistical analysis about the 32 selected electrodes for both conditions Upside-down (U) and Uncoordinated (J) vs. Normal (N).

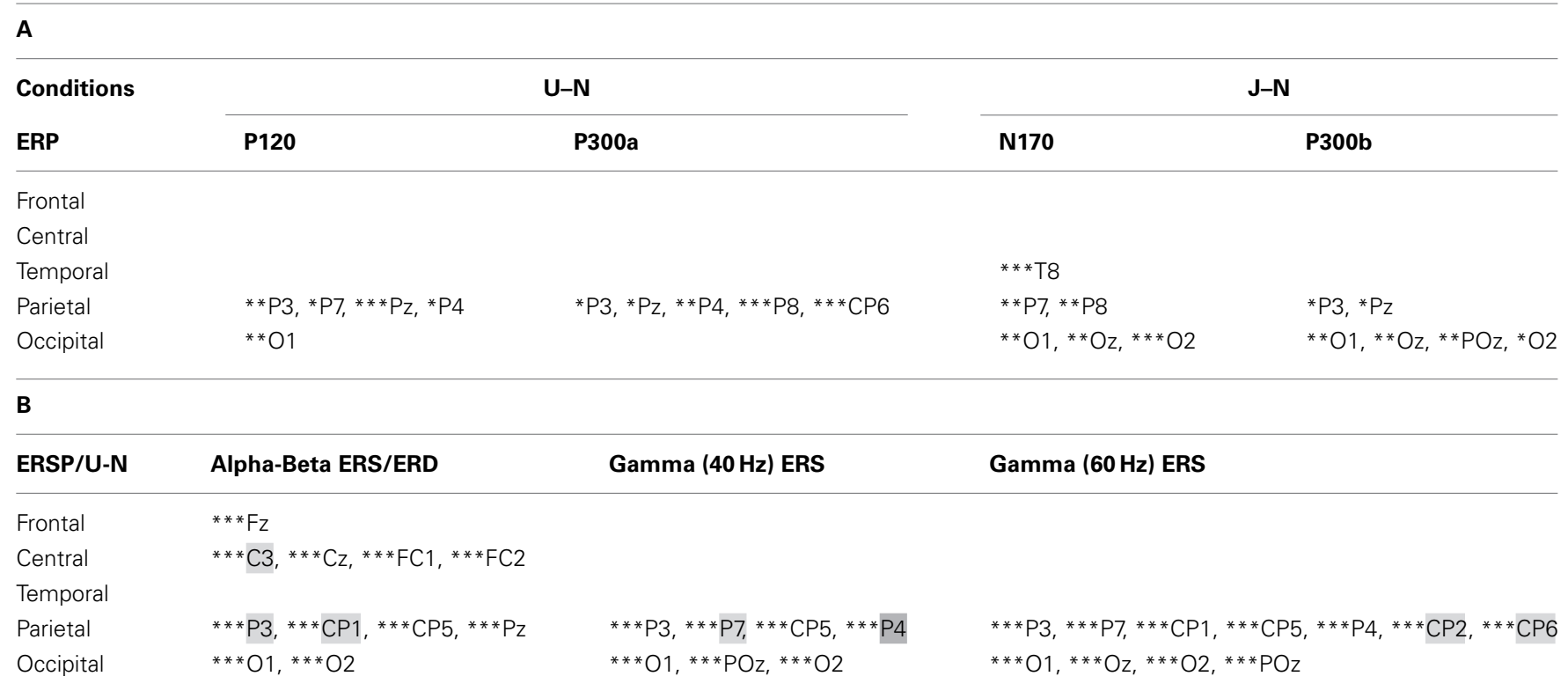

C

ERSP/J-N

Alpha-Beta ERS/ERD

Gamma (40-60 Hz) ERD

Frontal

Central

Temporal

Parietal

Occipital

Alpha-Beta ERS/ERD

${ }^{*}{ }^{*} \mathrm{C} 3,{ }^{* * *} \mathrm{C} 4$

${ }^{* *} \mathrm{C} 3,{ }^{* *} \mathrm{Cz}$

政,

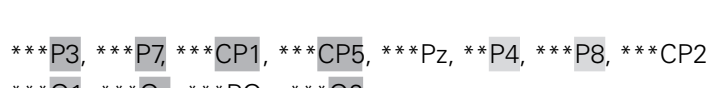

${ }^{* *} \mathrm{P} 3,{ }^{* *} \mathrm{P} 7,{ }^{* *} \mathrm{P} \mathrm{z},{ }^{* * *} \mathrm{CP} 1,{ }^{* *} \mathrm{CP} 5,{ }^{* *} \mathrm{CP} 2,{ }^{*}{ }^{*} \mathrm{CP} 6$

$* * * \mathrm{O} 1,{ }^{* * *} \mathrm{Oz},{ }^{* *} \mathrm{PO} z,{ }^{* *} \mathrm{O} 2$

***O $1,{ }^{* *} \mathrm{Oz},{ }^{* *} \mathrm{PO} z,{ }^{* *} \mathrm{O} 2$

D

\section{SSVEP}

U-N $300 \mathrm{~ms}$

J-N 400 ms

Frontal

Central

Temporal

Parietal

Occipital
${ }^{* *} \mathrm{C} 3,{ }^{*} \mathrm{C} z$
${ }^{*}{ }^{*} \mathrm{CP} 1,{ }^{*} \mathrm{P} 33,{ }^{*}{ }^{*} \mathrm{Pz},{ }^{*} \mathrm{P} 4,{ }^{*} \mathrm{CP} 2$
${ }^{*}{ }^{*} \mathrm{O} 1,{ }^{* *} \mathrm{O} z,{ }^{* *} \mathrm{PO} z,{ }^{* *} \mathrm{O} 2$
${ }^{* *}{ }^{*} \mathrm{CP} 5,{ }^{*} \mathrm{CP} 1,{ }^{*}{ }^{*} \mathrm{P} 3,{ }^{* *} \mathrm{Pz},{ }^{* *} \mathrm{P} 4,{ }^{*} \mathrm{CP} 2$
***O $1,{ }^{* * *} \mathrm{Oz},{ }^{* * *} \mathrm{PO} z,{ }^{* *} \mathrm{O} 2$

(A) ERP for P120, N170, P300a, and P300b amplitudes. (B) ERSP and ITC for U vs. N. (C) ERSP and ITC for $J$ vs. N. Only the electrodes showing significant results are represented $\left({ }^{* *} 0.001,{ }^{* *} 0.01\right)$. The reduction in theta phase locking (ITC) is indexed by gray shading (dark $p<0.001$, light $\left.p<0.01\right)$. (D) SSVEP behavior differences.

left part; Table 1). The reduction of the ascending phase slope of this negativity in the Upside-Down condition was accompanied over parieto-occipital regions by a power increase in beta-gamma band at about $250 \mathrm{~ms}$ and later by a power increase in gamma band $(60 \mathrm{~Hz})$ at about $400 \mathrm{~ms}$ (Figure 10B, left part). These effects were preceded by a decrease of theta-alpha bands ITC at about $120 \mathrm{~ms}$ with respect to the Normal condition (Figure 10B, left part).

The Uncoordinated condition showed a significant increase of the SSVEP negativity at about $400 \mathrm{~ms}$ with respect to the Normal condition (Figure 10A, right part; Table 1). This was preceded by an ERD in the theta-alpha band (Figure 10B) over parieto-occipital regions. While the higher amplitude of the first negative peak recorded in this condition remained under the significance level (Figure 10A, right part) it was accompanied by a significant increase of theta-alpha bands power at about $100 \mathrm{~ms}$ with respect to the Normal condition. These effects were followed by successive decrease and then increase of theta-alpha ITC respectively at about 350 and $450 \mathrm{~ms}$ (Figure 10B, right part).

\section{DISCUSSION}

To our knowledge, this work represents the first study on the dynamic neural response elicited by VR-animation of human walking. The presentation of the VR-animation elicits ERP components classically described in response to a visual stimulation (Jeffreys, 1996). We demonstrate significant changes in the amplitude of the P120 and P300a when the avatar 


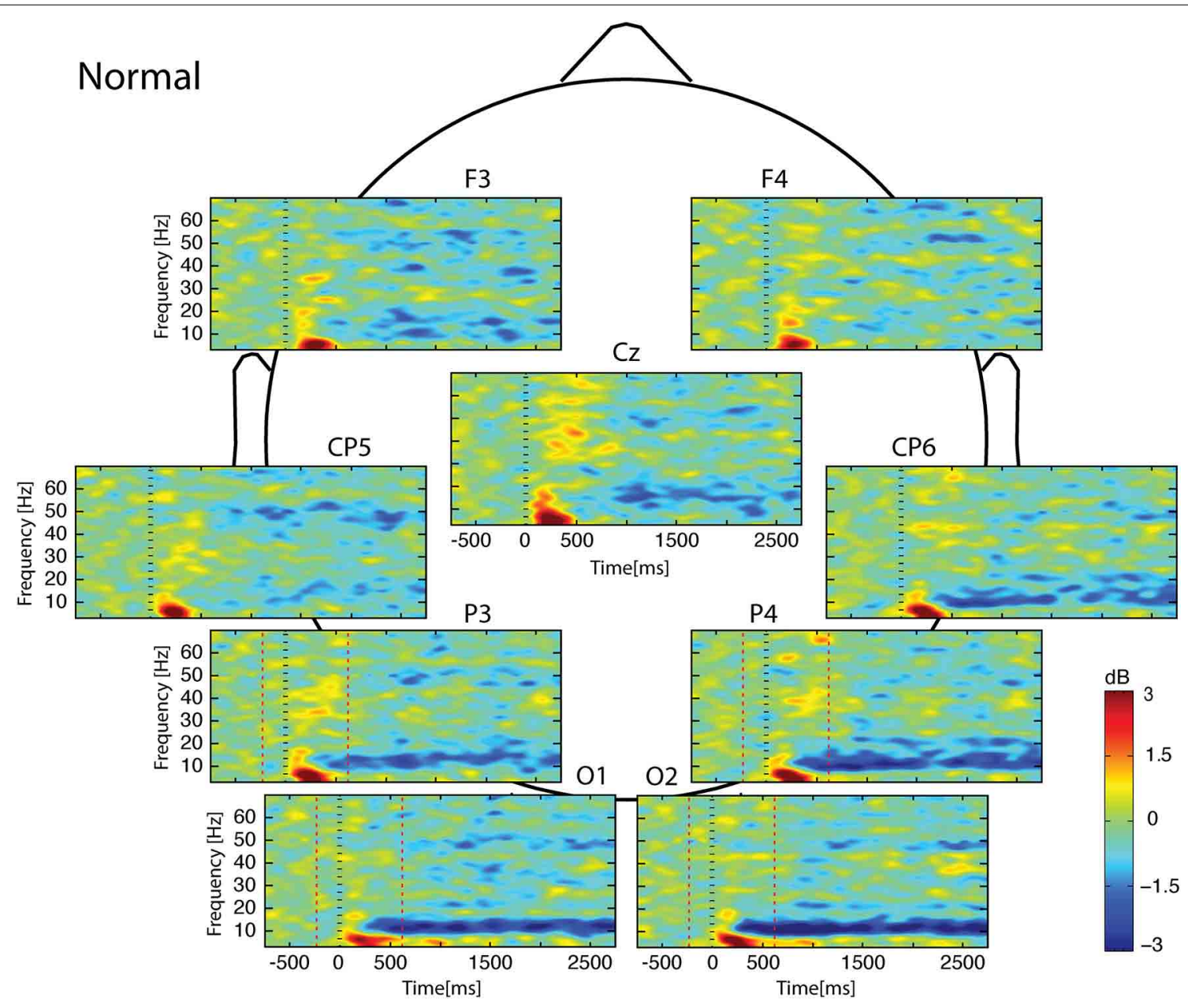

FIGURE 3 | Scalp ERSP on [-1000; 3000] ms in Normal condition. Rhythmic activity can be splits in two parts: [0; 500] ms which contains responses evoked by animation onset; and [500; 3000] ms of maintaining task. Note that bilateral alpha-beta ERD was continue from 200 to $3000 \mathrm{~ms}$, and gamma ERD at about $700 \mathrm{~ms}$, maintained for the $3000 \mathrm{~ms}$ in the left sensori-motor region. Red lines delimit epochs analyzed: [-200; 600] ms. was upside-down, and the N170 and P300b when the walking sequence was perturbed (Uncoordinated) with respect to the Normal condition.

The presence of the early alpha ERS characterize the Normal condition. The alpha-beta ERD was reinforced and the theta phase-locking was disturbed in Upside-down and Uncoordinated condition. As regards gamma oscillation, a contrasting situation was seen as its power was increased in association with the Upside-down animation and decreased with the Uncoordinated animation.

An SSVEP-like response oscillating at about $9 \mathrm{~Hz}$ was also described when the heel strike event was used as trigger, showing that the oscillating pattern is enhanced $300 \mathrm{~ms}$ after the heel strike event only in the Normal but not in the Upside-Down condition.

\section{ERP}

The present ERP components evoked by avatar observation are in accordance with those recorded in previous studies using point-light paradigm (Johansson, 1973). The timing of P120, N170, and P300 are commonly regarded as corresponding to the main three components P1 around $130 \mathrm{~ms}, \mathrm{~N} 1$ at $200 \mathrm{~ms}$ and N2 (P3 depending of the type and the placement of reference electrode) at 300-400 ms described in point-light walking studies (Hirai et al., 2003, 2005, 2009, 2013; Jokisch et al., 2005; Krakowski et al., 2011; Buzzell et al., 2013).

Although point-light and VR displays concern the same biological motion, VR display induced a stronger visual representation, including form and color than point-light walking. VR display conserved body structure in the Normal, Upside-down, and Uncoordinated conditions. This was not the case in point-light studies, where inverted condition associate form recognition to motion, and scramble condition deconstruct body form. In this context, the present VRparadigm offers the possibility to dissociate recognition of body form occurring at the first video frame, and motion coherence (smoothness, coordination, speed, etc.) produced by the successive frames. This allows to focus specifically on the effect induced by changing the frame of reference in Upsidedown and the global coherency of the walking motion in Uncoordinated. 


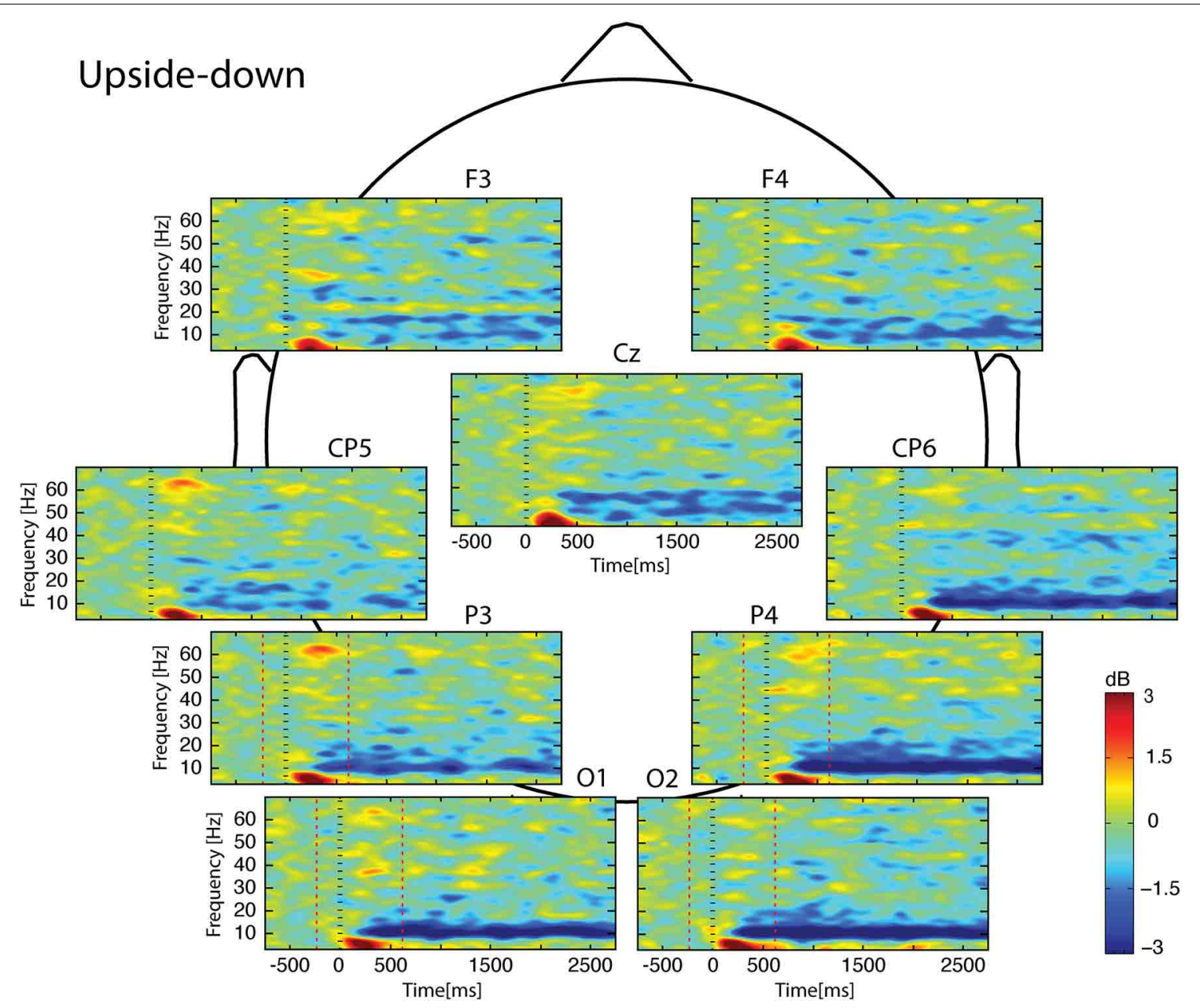

FIGURE 4 | Scalp ERSP on [-1000; 3000] ms in Upside-down condition. Rhythmic activity can be splits in two parts: $[0 ; 500] \mathrm{ms}$ which contains responses evoked by animation onset; and [500; 3000]ms of maintaining task. Note that bilateral alpha-beta ERD was continue from 200 to $3000 \mathrm{~ms}$. Red lines delimit epochs analyzed: $[-200 ; 600] \mathrm{ms}$.
The similarity of P120 evoked by the Normal and the Uncoordinated conditions is consistent with the fact that the first image is the same in these conditions. In contrast, pointlight studies showed a delay and a decrease in P1 response elicited by scramble condition with respect to upright condition (Hirai et al., 2009, 2013; Krakowski et al., 2011). These results support common interpretation that first component reflects a global representation coding of form (Baccus et al., 2009; Buzzell et al., 2013; White et al., 2014). However, the finding of decrease P120 in the Upside-down condition with respect to the Normal condition was not reported by previous point-light studies. The origin of this early alteration can be explained by both bottom-up and/or top-down process. Distinctions between these influences are not easy. The Normal presentation of the avatar may unconsciously induce an easy visual representation than the Upside-down mannequin which implies a mental transformation of the reference frame. In parallel, the repeated presentation of normal or inverted locomotion can predictively influence this early response by a top-down effect exerted by the frontal cortex to the primary visual cortex (Peyrin et al.,
2010; Cardin et al., 2011; Zanto et al., 2011; Ramalingam et al., 2013). However, previous studies suggest that explicitly attended tasks process does not appear to influence the earlier activity at about $100 \mathrm{~ms}$ (Krakowski et al., 2011; Buzzell et al., 2013).

Concerning later activation, $\mathrm{N} 1$ and $\mathrm{N} 2$ were generally related to integration of form and motion (Baccus et al., 2009; Buzzell et al., 2013; White et al., 2014). It is interesting to note that the effects of Uncoordinated condition on N170 (analogous to $\mathrm{N} 1$ in point-light studies) and of point-light scramble on N1 are comparable, as N170 was reduced in Uncoordinated condition as N1 in scramble condition (Hirai et al., 2003, 2013; Jokisch et al., 2005). This result suggests that N170 was mainly related to motion. In contrast, P300a (analogous to N2 in point-light studies) amplitude was the same in Normal and Uncoordinated conditions, whereas N2 was larger in upright point-light walker than point-light scramble (Jokisch et al., 2005; Hirai et al., 2013). Moreover, P300a amplitude was smaller in Upside-down than in Normal. This could also be related to the alteration of the SSVEP pattern occurring at this latency in the 


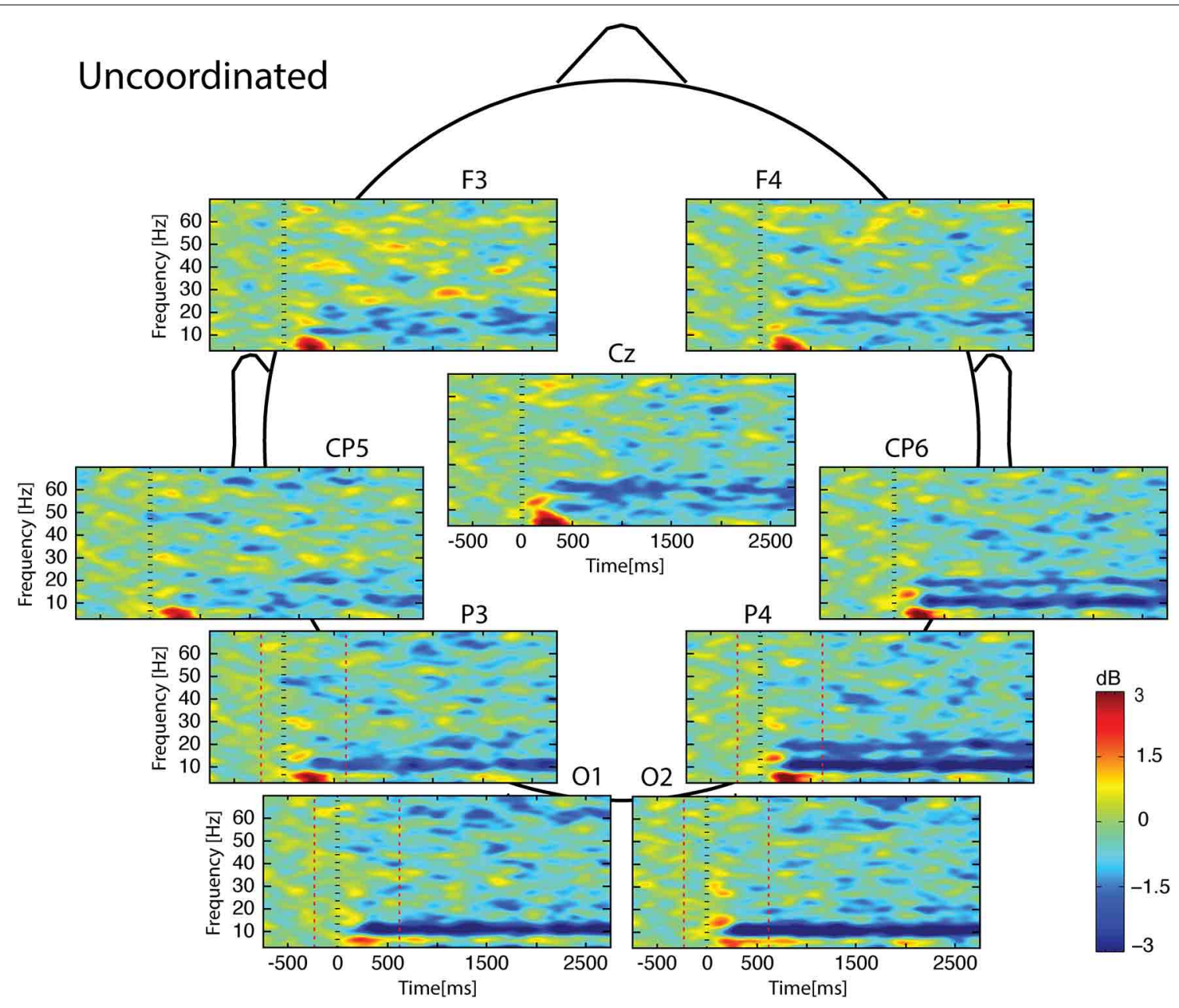

FIGURE 5 | Scalp ERSP on [-1000; 3000] $\mathrm{ms}$ in Uncoordinated condition. Rhythmic activity can be splits in two parts: [0; 500] ms which contains responses evoked by animation onset; and [500; 3000]ms of maintaining task. Note bilateral that alpha-beta ERD was continue from 200 to $3000 \mathrm{~ms}$. Red lines delimit epochs analyzed: $[-200 ; 600] \mathrm{ms}$.
Upside-down vs. Normal condition. Taken together these results suggest that P300a was mainly related to the global form of walking.

Finally, the effect we recorded on P300b and in the SSVEP at about the same latency in the Uncoordinated condition is comparable to the late phase describe by Krakowski et al. (2011), which was characterized by a greater positivity in response to upright and inverted point-light walker than point-light scramble. This last phase after $400 \mathrm{~ms}$ is generally considered as indexing a highorder representation coding (Krakowski et al., 2011). This effect observed in Uncoordinated suggests that P300b component is sensitive to coherence of motion rather to mere recognition of walking.

\section{ERSP AND ITC Alpha ERS/ERD}

The significant alpha ERS occurring at about $120 \mathrm{~ms}$ in the occipito-parietal regions characterized the Normal walking observation. It was followed by an alpha-beta ERD at $200 \mathrm{~ms}$, which extends throughout the video. This was significantly more pronounced in Upside-down and Uncoordinated conditions than in Normal.

The first alpha ERS is in accordance with recent studies showing similar transient alpha increase in response to upright facial motion (Girges et al., 2014). The suppression of the early alpha ERS in Upside-down suggest that the inversion of the body presentation rapidly affect the early visual process. However, similar alteration found for the Uncoordinated condition while the first image was exactly the same suggests a top-down influence. Alpha oscillation has been interpreted as reflecting global inhibition of the cortex, improving behavioral performance by facilitation of the cognitive control (Klimesch et al., 1996, 2003, 2007; Klimesch, 1999, 2012; Cheron et al., 2006; Haegens et al., 2010). Thus, increase in alpha power (ERS) may participate to a general clearance of noise or distracting event in order to selectively update relevant incoming information (Sadaghiani et al., 2012), and access to memory (Klimesch, 2012). In this context, suppression of alpha ERS in Upside-down and Uncoordinated conditions would be correlated with increase of attention to motion cue and involvement of cognitive resources. 

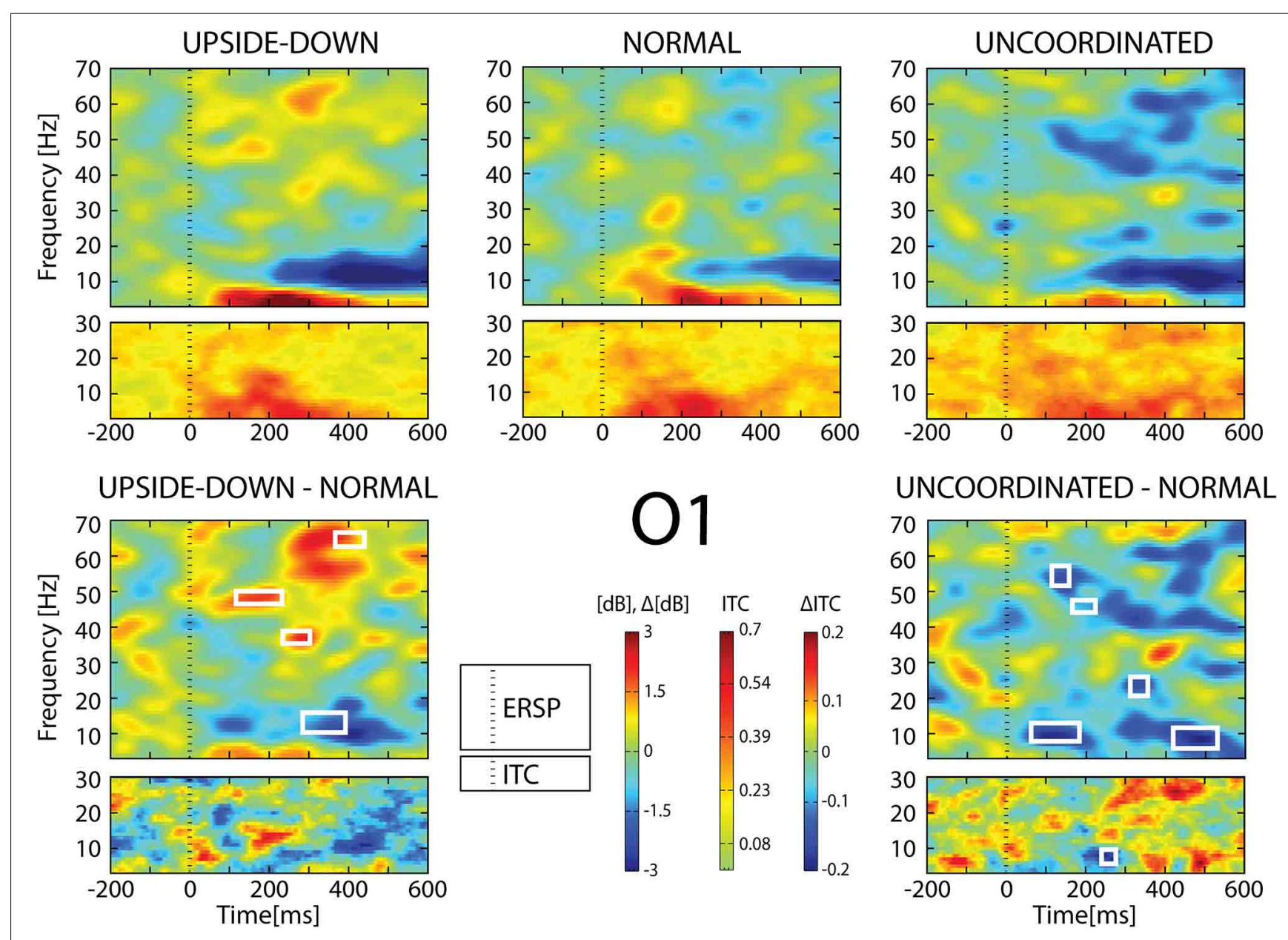

FIGURE 6 | ERSP and ITC from 01 electrode. The upper panel shows the ERSP and ITC in each three conditions. The lower panel shows difference Upside-down-Normal (left), and Uncoordinated-Normal (right) for ERSP and ITC. Areas of statistical significances ( $p<0.001)$ are marked by white squares.

The next alpha ERD are in line with previous research showing decrease in alpha band power during perception of human motion (Cochin et al., 1998; Ulloa and Pineda, 2007). This was generally related to the desynchronization of mirror neurons activity as studied with EEG and fMRI combination (Arnstein et al., 2011), and would reflect a release from inhibition. However, it is interesting to note that our results are in contrast to studies of face perception (Girges et al., 2014), which report a greater alpha ERD in response to upright facial motion than in inverted condition. This difference between face and body motion recognition may be explain by high specialization of the brain to face recognition, and in particular to treatment of semantic content of facial gesture (Rojas et al., 2011). According to Klimesch et al. (1997, 1999, 2012), the alpha ERD increased as a function of the semantic content of retrieved information from the storage system. In our study, each stimulus has the same semantic content as a walking avatar. In this context, amplification of alpha ERD would indicate a recruitment of the mirror neurons system in order to recognize or predicted observed motion, by transformation of reference frame (in Upside-down) and reconstruction of motion (in Uncoordinated). The enhancement of the alpha ERD in Upside-down and Uncoordinated condition might then facilitate a dynamical process throughout the neural network involved in alpha rhythm generation evoked by the Normal walking avatar.

\section{Theta ERS}

The present ITC analysis shows that phase locking occur mainly in the theta range (peaked at $\sim 5 \mathrm{~Hz}$ ). However, as it is classically the case, this is not a pure phase locking because it was accompanied by theta ERS throughout all electrodes. Indeed, the visual evoked potentials (P100-N200) elicited by the classical checkerboard pattern or by more complex visual stimuli were accompanied by a clear theta ERS and related ITC (Klimesch et al., 2004; Cheron et al., 2014). Although present in each of the three present conditions in the $100-400 \mathrm{~ms}$ time period, the theta ITC was significantly perturbed in both Upside-down and Uncoordinated condition, while theta ERS were not significantly different. This indicates that the recognition of Normal walking is accompanied by a stronger theta phase locking peaking between 200 and $300 \mathrm{~ms}$. 


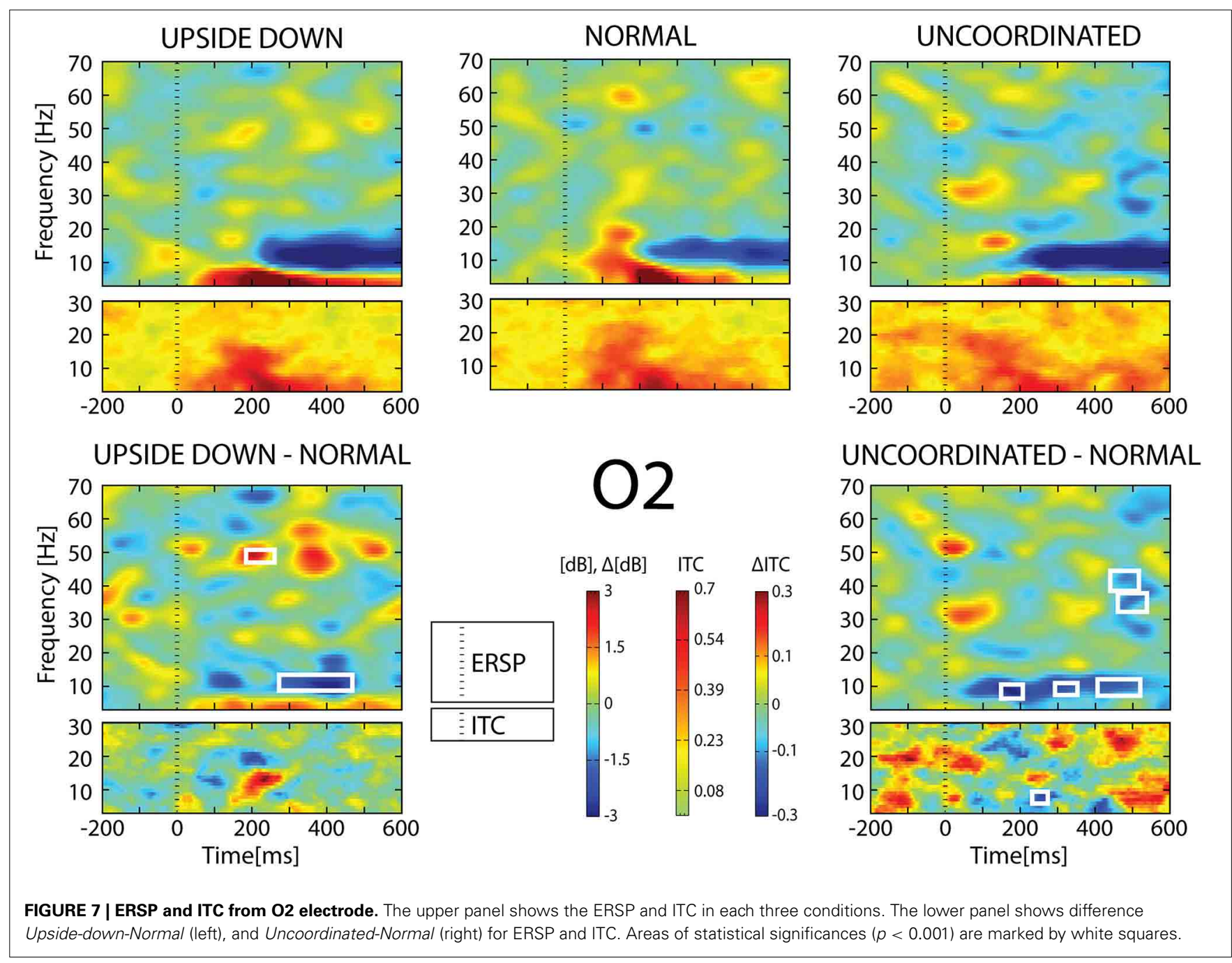

In humans the theta EEG rhythm $(4-7 \mathrm{~Hz})$ was initially defined as an intermediate rhythm between delta and alpha (Walter and Dovey, 1944; Mitchell et al., 2008). Later, the term FM-theta (FM for fronto-midline) was introduced by Ishihara and Yoshi (1972) when EEG was recorded during arithmetic task (Ishihara and Yoshi, 1972). Later, the presence of FM-theta during arithmetic and musical activities was demonstrated with MEG (Sasaki et al., 1996a,b,c). The midline frontal areas, such as the anterior cingulate cortex encompassing the lateral part of the prefrontal cortex are commonly cited as potential generators of the FM-theta (Gevins et al., 1997; Mizuhara et al., 2004; Sauseng et al., 2007).

In rat hippocampal regions, theta oscillation $(3-9 \mathrm{~Hz})$ is recognized to play an important role in the phase precession of the place cells firing assuming cued recall of the coming positions along the locomotion path of the rat (O'Keefe and Recce, 1993). The intrinsic theta generator of the hippocampal cortex is reinforced by the extrinsic theta pacemaker situated in the medial septal nucleus and allows a large-scale synchronization of theta oscillations in the hippocampus (Kocsis et al., 1999; Buzsáki, 2002). Theta oscillation is not restricted to the hippocampus but also emerges in different cortical areas in the rat (Leung and Borst, 1987; Silva et al., 1991). The ability of different cortical regions to produce theta is supported by slice recording demonstrating that theta oscillation may be produced by the activation of the NMDA receptors of the layer 5 (Silva et al., 1991; Flint and Connors, 1996) as well as by cholinergic activation of interneurons (Blatow et al., 2003).

Although human theta rhythm is not as robust as in the rat hippocampus, the ability of the human cortex to produce theta oscillation is now well recognized. It has been related to sensorimotor integration (Caplan et al., 2001), navigation (Kahana et al., 1999), memory load (Howard et al., 2003) and working memory (Raghavachari et al., 2001, 2006; Liebe et al., 2012). Interestingly, all the different phases of virtual movement during a navigation game induced an increase of $4-8 \mathrm{~Hz}$ oscillation in both the hippocampus and neocortex in human (Ekstrom et al., 2005). Although the present experiment involves the observation of human locomotion it cannot be assumed that the recorded theta oscillations are specifically related to locomotion per se. Indeed, theta oscillations are now considered as a basic physiological element involved in global oscillatory synchronization processes 

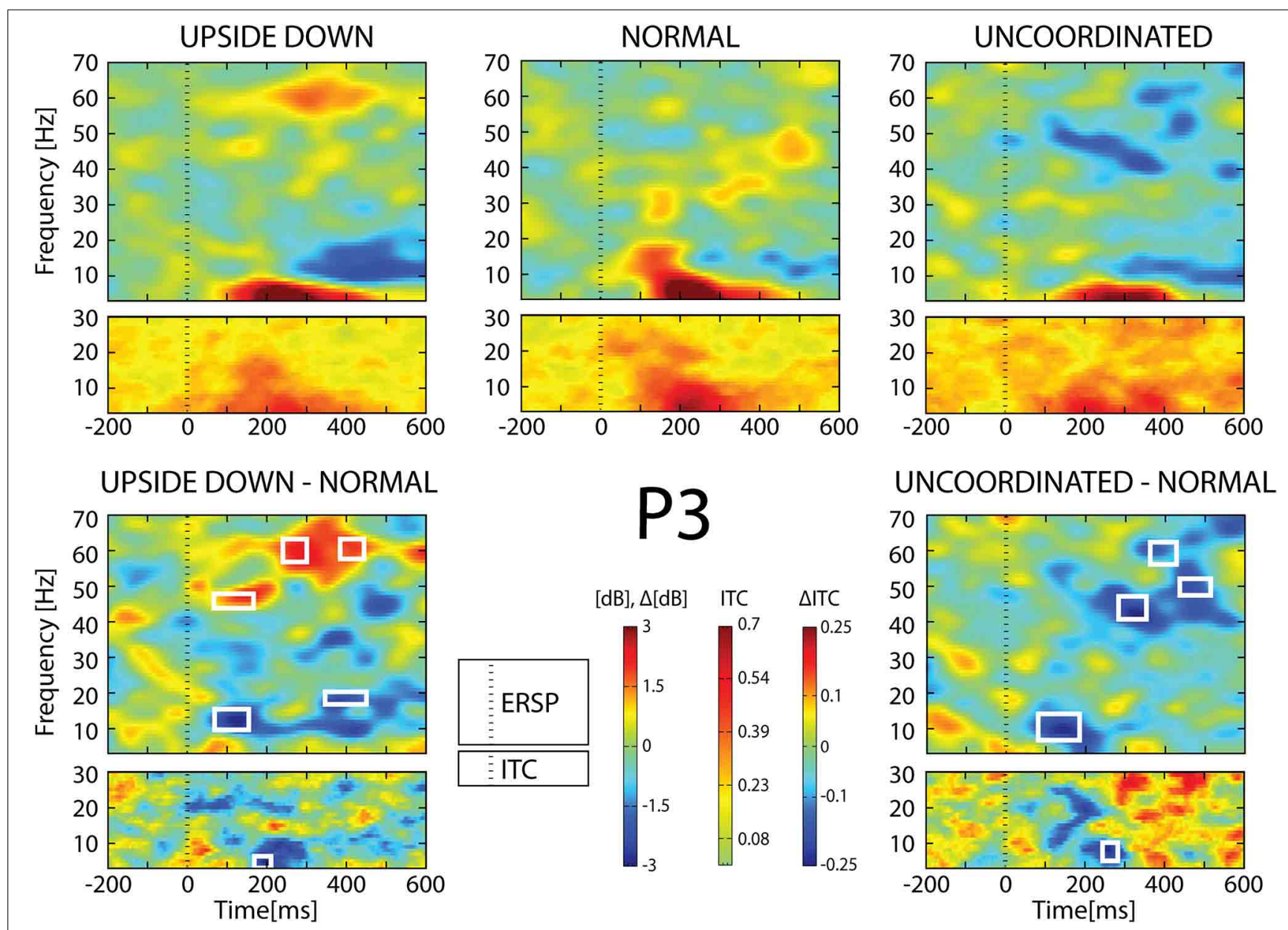

FIGURE 8 | ERSP and ITC from P3 electrode. The upper panel shows the ERSP and ITC in each three conditions. The lower panel shows difference Upside-down-Normal (left), and Uncoordinated-Normal (right) for ERSP and ITC. Areas of statistical significances ( $p<0.001)$ are marked by white squares.

linking together multiple brain regions (Buzsáki and Draguhn, 2004; Fries, 2005). For example, the multiplicity of functional roles for this oscillation was demonstrated by the fact that the amplitude of theta power recorded over the temporal and frontal cortex predicted the behavioral performance of the subject (Sederberg et al., 2003). A recent MEG study demonstrated that hippocampal-prefrontal theta synchronization plays a mnemonic guidance in human decision-making (Guitart-Masip et al., 2013). Single neurons and local field potential recordings in the human medial temporal lobe show that theta phase locking reflects a global activation providing a temporal window for the conscious recognition (Rey et al., 2014). At a lower hierarchical level closer to the present observational task, theta oscillation is related to the perception of color shape of object and visual attention (Fries et al., 2001b). It is also involved in different sensory modalities to provide meaningful chunks of neuronal signals allowing subsequent decoding for an enhanced perception. In our case, such theta oscillation may thus be viewed as taking part of time-division multiplexing mechanism representing sequential information upon which a neuronal code may emerge by cross-frequency interaction with faster (gamma) oscillation (Akam and Kullmann, 2014).

\section{Gamma modulation}

Gamma oscillation $(30-100 \mathrm{~Hz})$ occupies a privileged position in cognitive neuroscience. The current understanding of gamma oscillation points to its emergence from the synchronous activity of a large ensemble of firing neurons (Eckhorn et al., 1988; Gray et al., 1989; Jensen and Colgin, 2007). It is central to the binding theory, in which gamma oscillations combine different features in a visual scene to form a coherent percept (Singer, 1999). Unexpectedly, our results show that Upside-down condition elicited gamma power increase at about 150 and $400 \mathrm{~ms}$ and a gamma ERD at the same latency in the Uncoordinated condition. This contrasting behavior of gamma oscillation is interesting because these oscillations are considered to underlie perception of coherent stimuli. These data are in accordance to previous MEG study showing enhancements in gamma rhythm at $100 \mathrm{~ms}$ after display onset in upright and inverted pointlight walker (Pavlova et al., 2004). However, in the latter study additional gamma peak appeared only for upright point-light walker at 130 and $170 \mathrm{~ms}$. Another study of the same group reported increased gamma activity in the left parieto-occipital region at $80 \mathrm{~ms}$, with additional peaks in attended point-light walker on the right parietal and temporal cortex at 120 and 


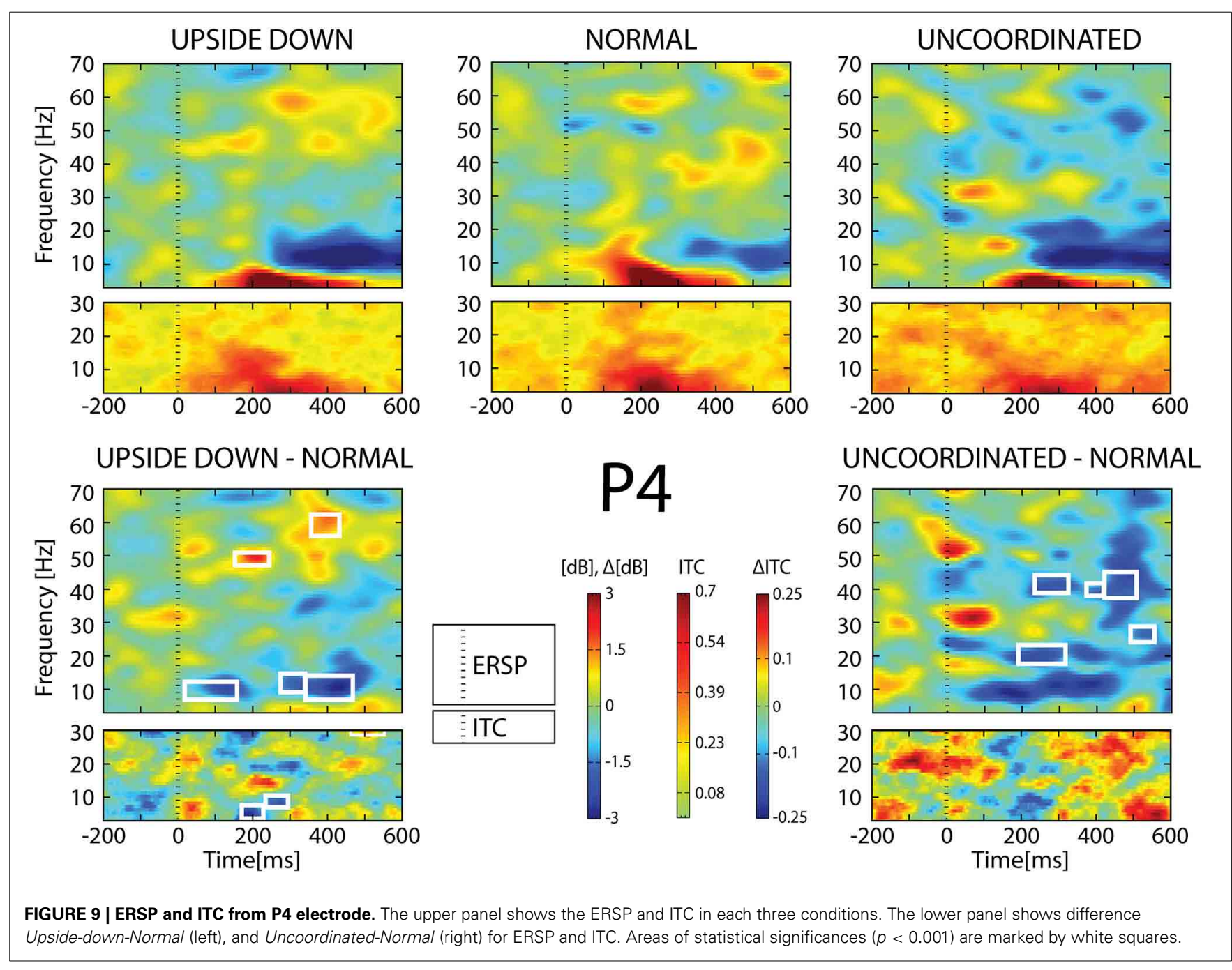

$155 \mathrm{~ms}$, respectively (Pavlova et al., 2006). The present results are in agreement with the data of Tallon-Baudry et al. (1996), where they demonstrated the presence of non-phase-locked gamma activation $(60 \mathrm{~Hz})$ at about $300-400 \mathrm{~ms}$ after the presentation of an illusory Kanizsa triangle figure (Tallon-Baudry et al., 1996). In this experiment, the gamma activity was stronger when the recognition task required additional mental reconstruction (stronger gamma oscillation for illusory triangle than normal triangle). In our present study, a non-phase-locked $60 \mathrm{~Hz}$ power increase occurred at the same latency only when the walking avatar was presented in Upside-down configuration. The subject was not instructed to perform any mental task but implicit recognition can recruit gamma activity for unconscious and conscious neuronal process (Aru et al., 2012; Vidal et al., 2014). The complex interplay between these neuronal qualia occupies a central position in cognitive neuroscience (Kandel, 2013). In the context of the Global Workspace Theory, serial and parallel processing take part from the widespread treatment of unconscious information to the emergence of consciousness (Baars, 1997; Dehaene and Naccache, 2001; Baars et al., 2013; Dehaene et al., 2014).
From a physiological perspective, experiments and modeling have demonstrated that gamma rhythms emerge from the interaction between local excitation and inhibition (Traub et al., 1997; Brunel and Wang, 2003; Kang et al., 2010), in which the gap junctions between interneurons play a pivotal role in ensuring gamma oscillation coherence (Traub et al., 2003; Whittington and Traub, 2003). In macaque, high density electrocorticography recording (Brunet et al., 2013) demonstrated that natural viewing induced a strong gamma oscillation $(50-80 \mathrm{~Hz})$ over most of the recorded visual cortex including V1 and V4 but not over most of the remaining cortex extending from superior temporal sulcus to the anterior part of the arcuate sulcus. The functional link between neuronal spikes and local field potential oscillation has been well documented in different preparations, demonstrating that spike-field coherence in the gamma-band frequency is accompanied by power enhancement of the gamma rhythm (Fries et al., 2001a,b, 2002, 2008). It was also demonstrated that when visual stimuli are moving smoothly, the visual cortex produces neuronal synchronization in the gamma-frequency band (Friedman-Hill et al., 2000). This gamma synchronization is considered as a key element for signal transmission to 


\section{A UPSIDE DOWN}

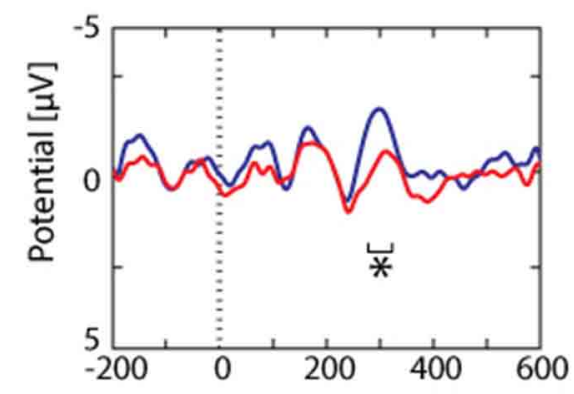

NORMAL

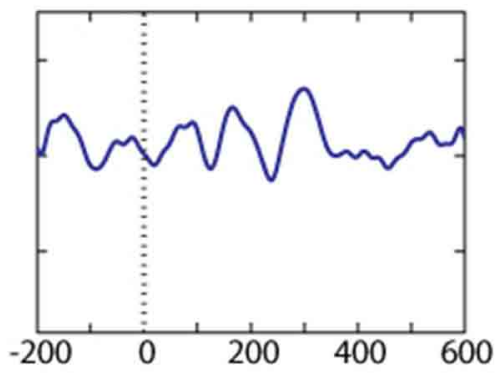

UNCOORDINATED

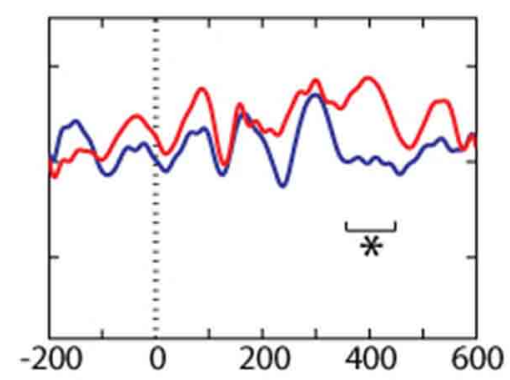

B
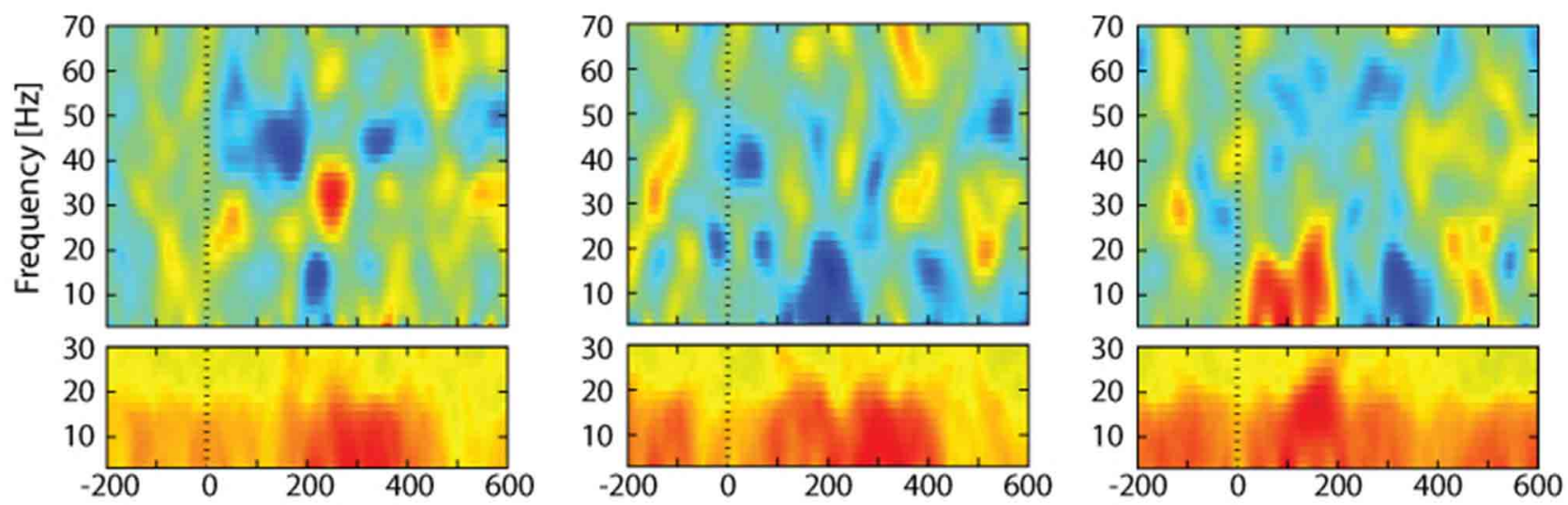

UPSIDE DOWN - NORMAL
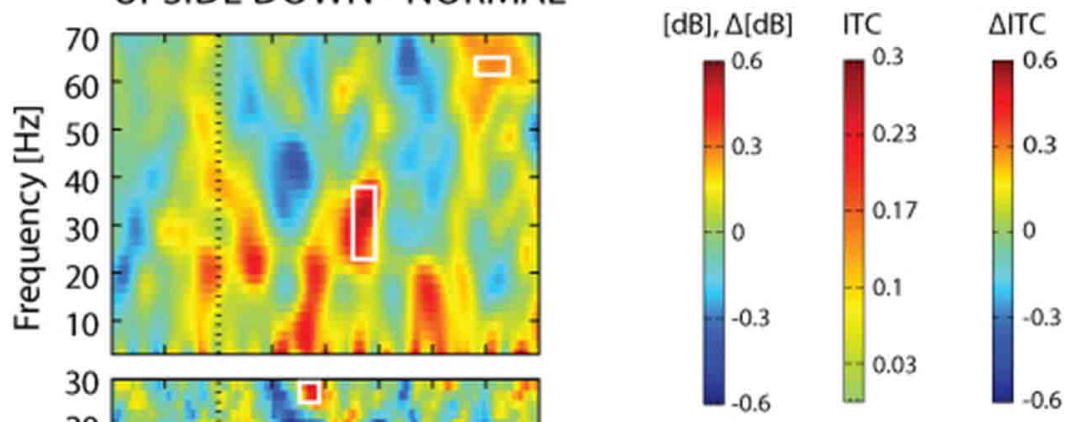

UNCOORDINATED- NORMAL
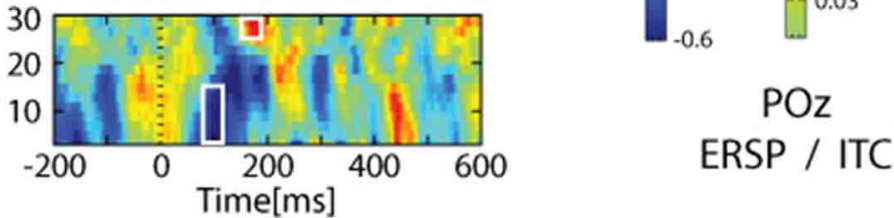
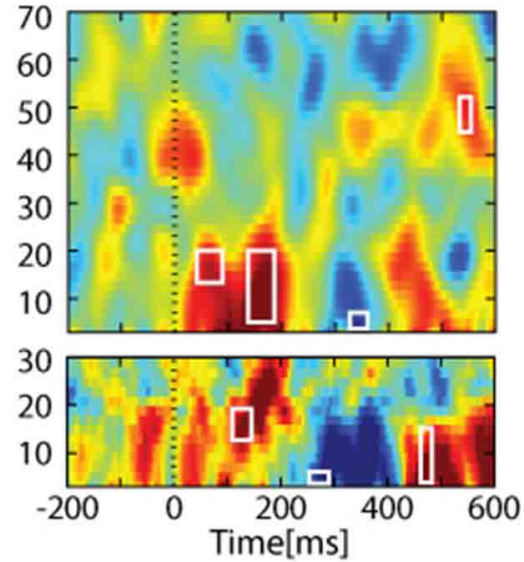

FIGURE 10 | SSVEP analysis from POz electrode. (A) Grand average trace corresponding to 16 subjects and about $2065 \pm 26$ trials for each condition. The heel strike of the right leg was used as trigger. Note the oscillating pattern at about $9 \mathrm{~Hz}$ and the superimposition of the Normal condition (blue trace) over the Upside-down (red trace, left part) and the Uncoordinated condition (red trace, right part). Areas of statistical significance $(p<0.001)$ are indicated by an asterisk. (B) The upper panel shows ERSP and ITC analysis of the same SSVEP data for the three respective conditions presented in (A). The lower panel shows, ERSP and ITC differences Upside-down-Normal (left), and Uncoordinated-Normal (right). Areas of statistical significance $(p<0.001)$ are marked by white squares. postsynaptic targets and to assume the continuity of the visual message (Fries, 2009).

In this context, the gamma ERD recorded during the Uncoordinated condition could be explained by a previous experience of Kruse and Eckhorn (1996) realized in the primary visual cortex of the cat. When a smooth movement of the visual field was presented it induced gamma oscillation, but when the smooth movement was intermingled with sudden random acceleration in and against the original direction of the smooth movement the gamma oscillations disappeared (Kruse and Eckhorn, 1996). This 
latter situation corresponds to the present Uncoordinated condition where gamma ERD replace gamma ERS present in Normal and Upside-down condition. The smoothness aspect of the walking video for both Normal and Upside-down presentations induces gamma oscillation while the sudden "Uncoordinated" image desynchronizes the neuronal population responsible for the gamma oscillation. In addition, Kruse and Eckhorn (1996) have demonstrated an inverse relationship between the decrease in gamma power and an increase in the stimulus-locked responses in lower frequency band (Kruse and Eckhorn, 1996).

Following the canonical microcircuit model (Bastos et al., 2012) based on intracellular recordings in cat visual cortex incorporating the neuronal sources of forward and backward connections in cortical hierarchies, it was proposed that the superficial pyramidal neurons generate gamma responses whereas deep pyramidal neurons generate alpha and beta dynamics. The visual cortex has been suggested to act as a dynamic filter of the visual input where stimulus properties like movement, contrast, localization and size of visual cues may modify the configuration of gamma oscillation (Gray et al., 1989; Ray and Maunsell, 2010; Brunet et al., 2013; Roberts et al., 2013). Among these stimulus properties, contrast is able to enhanced the signal-to-noise ratio of the sensory input inducing an increase in the postsynaptic gain of superficial pyramidal cells implicate in gamma oscillation (Feldman and Friston, 2010). Although, the same avatar was used here in the three different conditions the kinematic change of the Uncoordinated condition induced a significant increase in the dynamic contrast at the latency of $400 \mathrm{~ms}$ and may thus explain the late gamma ERD present in this condition. The spatial summation and the receptive field organization in V1 depend on contrast stimulus (Sceniak et al., 2002). The effects of contrast on the induced rhythms are complex and specifically influence the postsynaptic gain of neuronal populations, the strength of intrinsic and horizontal connectivity which can be differentially engaged depending on stimulus properties (Pinotsis et al., 2014). These authors have reported that the increase in visual contrast induces an increase of gamma peak frequency (from 46 to $58 \mathrm{~Hz}$ ) accompanied by a decrease in gamma power. This contrast effect on the gamma power must be taken in account in the present gamma ERD and is complementary to the previous Kruse and Eckhorn's (1996) reported effect on the gamma power when the visual movement is Uncoordinated.

\section{SSVEP}

In order to strengthen the ERP, ERSP, and ITC studies of the transient presentation of the walking video, a SSVEP approach was made by using the heel strike events as the synchronized item of the video images occurring at every $100 \mathrm{~ms}$. SSVEP offer many advantages in comparison to ERP, including better signal-to-noise ratio with a clear peak in the FFT occurring at the frequency of interest and some of its harmonics, and greater number of averaged items in a shorter period of time. SSVEP are classically obtained by using neutral LED or LCD image flashing between 1 and $100 \mathrm{~Hz}$ inducing resonance phenomena. In the present study, the SSVEP was not obtained by directly triggering all of the images occurring at $10 \mathrm{~Hz}$ but by using a specific event of the avatar locomotion corresponding to the initiation of the step cycle.
SSVEP is classically considered as an oscillatory response of the visual cortex evoked by contrast or luminance-modulated stimuli that drive the neural response at the imposed frequency of the constant peripheral stimulation (Regan, 1966; Müller et al., 1998). SSVEP are not only imposed by the physical properties of the stimulus but also depends on the brain state, task related-process, bottom-up and top-down influences (Müller et al., 1998; Keil et al., 2003; Andersen and Müller, 2010). This oscillatory pattern is a strong steady state potential that mainly arises from the occipital area, with strong contribution from the early visual cortex but also from more extended parts of the visual system including higher visual areas (Müller et al., 1997; Di Russo et al., 2007). This partly explains why SSVEP approach is increasingly used in cognitive and affective neurosciences to study face processing including face identification and decoding of facial emotional expressions (McTeague et al., 2011; Ales et al., 2012; Gruss et al., 2012; Rossion et al., 2012). To our knowledge, the present study is the first to use a walking avatar video for inducing SSVEP-like response. It showed specific amplitude enhancement of the oscillatory pattern and the related spectral perturbation at a precise time in relation to a kinematic event. Although no direct comparison can be made between SSVEP and ERP results, it is interesting to highlight the convergence of both types of results with regard to significant changes in the EEG brain rhythms at about the latency of $300 \mathrm{~ms}$ when the same avatar video was presented in Upside-down vs. Normal condition. The reported differences in the SSVEP configuration and rhythmic alteration (early theta-alpha ERS and late gamma ERS) in the Uncoordinated condition can be due to the higher dynamic contrast of this condition with respect to the other two conditions.

\section{ACKNOWLEDGMENTS}

We wish to thank Cal3D team for providing us with the original stimuli. We thank all volunters for their participation. This work was funded by the Belgian Federal Science Policy Office, the European Space Agency (AO-2004,118), the Belgian National Fund for Scientific Research (FNRS), the research funds of the Universite Libre de Bruxelles and of the Université de Mons (Belgium), the FEDER support (BIOFACT), the MINDWALKER project (FP7-2007-2013) supported by the European Commission, and the NeuroAtt BIOWIN project supported Walloon Country. The scientific responsibility rests with its author(s).

\section{REFERENCES}

Akam, T., and Kullmann, D. M. (2014). Oscillatory multiplexing of population codes for selective communication in the mammalian brain. Nat. Rev. Neurosci. 15, 111-122. doi: 10.1038/nrn3668

Ales, J. M., Farzin, F., Rossion, B., and Norcia, A. M. (2012). An objective method for measuring face detection thresholds using the sweep steady-state visual evoked response. J. Vis. 12:18. doi: 10.1167/12.10.18

Andersen, S. K., and Müller, M. M. (2010). Behavioral performance follows the time course of neural facilitation and suppression during cued shifts of feature-selective attention. Proc. Natl. Acad. Sci. U.S.A. 107, 13878-13882. doi: 10.1073/pnas.1002436107

Arnstein, D., Cui, F., Keysers, C., Maurits, N. M., and Gazzola, V. (2011). $\mu$ suppression during action observation and execution correlates with BOLD in dorsal premotor, inferior parietal, and SI cortices. J. Neurosci. 31, 14243-14249. doi: 10.1523/JNEUROSCI.0963-11.2011 
Aru, J., Axmacher, N., Do Lam, A. T. A., Fell, J., Elger, C. E., Singer, W., et al. (2012). Local category-specific gamma band responses in the visual cortex do not reflect conscious perception. J. Neurosci. 32, 14909-14914. doi: 10.1523/JNEUROSCI.2051-12.2012

Avanzini, P., Fabbri-Destro, M., Campi, C., Pascarella, A., Barchiesi, G., Cattaneo, L., et al. (2013). Spatiotemporal dynamics in understanding handobject interactions. Proc. Natl. Acad. Sci. U.S.A. 110, 15878-15885. doi: 10.1073/pnas.1314420110

Avanzini, P., Fabbri-Destro, M., Dalla Volta, R., Daprati, E., Rizzolatti, G., and Cantalupo, G. (2012). The dynamics of sensorimotor cortical oscillations during the observation of hand movements: an EEG study. PLoS ONE 7:e37534. doi: 10.1371/journal.pone.0037534

Baars, B. J. (1997). Spatial brain coherence during the establishment of a conscious event. Conscious. Cogn. 6, 1-2. doi: 10.1006/ccog.1996.0289

Baars, B. J., Franklin, S., and Ramsoy, T. Z. (2013). Global workspace dynamics: cortical "binding and propagation" enables conscious contents. Front. Psychol. 4:200. doi: 10.3389/fpsyg.2013.00200

Baccus, W., Mozgova, O., and Thompson, J. C. (2009). Early integration of form and motion in the neural response to biological motion. Neuroreport 20, 1334-1338. doi: 10.1097/WNR.0b013e328330a867

Bastos, A. M., Usrey, W. M., Adams, R. A., Mangun, G. R., Fries, P., and Friston, K. J. (2012). Canonical microcircuits for predictive coding. Neuron 76, 695-711. doi: 10.1016/j.neuron.2012.10.038

Blake, R., and Shiffrar, M. (2007). Perception of human motion. Annu. Rev. Psychol. 58, 47-73. doi: 10.1146/annurev.psych.57.102904.190152

Blatow, M., Rozov, A., Katona, I., Hormuzdi, S. G., Meyer, A. H., Whittington, M. A., et al. (2003). A novel network of multipolar bursting interneurons generates theta frequency oscillations in neocortex. Neuron 38, 805-817. doi: 10.1016/S0896-6273(03)00300-3

Braadbaart, L., Williams, J. H. G., and Waiter, G. D. (2013). Do mirror neuron areas mediate mu rhythm suppression during imitation and action observation? Int. J. Psychophysiol. 89, 99-105. doi: 10.1016/j.ijpsycho.2013. 05.019

Brunel, N., and Wang, X.-J. (2003). What determines the frequency of fast network oscillations with irregular neural discharges? I. Synaptic dynamics and excitation-inhibition balance. J. Neurophysiol. 90, 415-430. doi: 10.1152/jn.01095.2002

Brunet, N., Bosman, C. A., Roberts, M., Oostenveld, R., Womelsdorf, T., De Weerd, P., et al. (2013). Visual cortical gamma-band activity during free viewing of natural images. Cereb. Cortex. doi: 10.1093/cercor/bht280. [Epub ahead of print].

Brunner, C., Delorme, A., and Makeig, S. (2013). Eeglab-an open source matlab toolbox for electrophysiological research. Biomed. Tech. (Berl). doi: 10.1515/bmt-2013-4182. [Epub ahead of print].

Buzsáki, G. (2002). Theta oscillations in the hippocampus. Neuron 33, 325-340. doi: 10.1016/S0896-6273(02)00586-X

Buzsáki, G., and Draguhn, A. (2004). Neuronal oscillations in cortical networks. Science 304, 1926-1929. doi: 10.1126/science.1099745

Buzzell, G., Chubb, L., Safford, A. S., Thompson, J. C., and McDonald, C. G. (2013). Speed of human biological form and motion processing. PLoS ONE 8:e69396. doi: 10.1371/journal.pone.0069396

Caplan, J. B., Madsen, J. R., Raghavachari, S., and Kahana, M. J. (2001). Distinct patterns of brain oscillations underlie two basic parameters of human maze learning. J. Neurophysiol. 86, 368-380.

Cardin, V., Friston, K. J., and Zeki, S. (2011). Top-down modulations in the visual form pathway revealed with dynamic causal modeling. Cereb. Cortex 21, 550-562. doi: 10.1093/cercor/bhq122

Cebolla, A. M., De Saedeleer, C., Bengoetxea, A., Leurs, F., Balestra, C., d' Alcantara, P., et al. (2009). Movement gating of beta/gamma oscillations involved in the N30 somatosensory evoked potential. Hum. Brain Mapp. 30, 1568-1579. doi: 10.1002/hbm.20624

Cebolla, A. M., Palmero-Soler, E., Dan, B., and Cheron, G. (2014). Modulation of the N30 generators of the somatosensory evoked potentials by the mirror neuron system. Neuroimage 95C, 48-60. doi: 10.1016/j.neuroimage.2014.03.039

Cheng, Y.-W., Tzeng, O. J. L., Hung, D., Decety, J., and Hsieh, J.-C. (2005). Modulation of spinal excitability during observation of bipedal locomotion. Neuroreport 16, 1711-1714. doi: 10.1097/01.wnr.0000183325.13618.5f

Cheron, G., Cebolla, A. M., De Saedeleer, C., Bengoetxea, A., Leurs, F., Leroy, A., et al. (2007). Pure phase-locking of beta/gamma oscillation contributes to the
N30 frontal component of somatosensory evoked potentials. BMC Neurosci. 8:75. doi: 10.1186/1471-2202-8-75

Cheron, G., Leroy, A., De Saedeleer, C., Bengoetxea, A., Lipshits, M., Cebolla, A., et al. (2006). Effect of gravity on human spontaneous $10-\mathrm{Hz}$ electroencephalographic oscillations during the arrest reaction. Brain Res. 1121, 104-116. doi: 10.1016/j.brainres.2006.08.098

Cheron, G., Leroy, A., Palmero-Soler, E., De Saedeleer, C., Bengoetxea, A., Cebolla, A.-M., et al. (2014). Gravity influences top-down signals in visual processing. PLoS ONE 9:e82371. doi: 10.1371/journal.pone.0082371

Cochin, S., Barthelemy, C., Lejeune, B., Roux, S., and Martineau, J. (1998). Perception of motion and qEEG activity in human adults. Electroencephalogr. Clin. Neurophysiol. 107, 287-295. doi: 10.1016/S0013-4694(98) 00071-6

Crompton, R. H., Sellers, W. I., and Thorpe, S. K. S. (2010). Arboreality, terrestriality and bipedalism. Philos. Trans. R. Soc. Lond. B Biol. Sci. 365, 3301-3314. doi: 10.1098/rstb.2010.0035

Csibra, G. (2007). "Action mirroring and action interpretation: an alternative account," in Sensorimotor Foundations of Higher Cognition. Attention and Performance XXII, eds P. Haggard, Y. Rosetti, and M. Kawato (Oxford; New York, NY: Oxford University Press), 435-459.

Darwin, C. (1872). The Expression of the Emotions in Man and Animals. 1st Edn. London: John Murray.

De Gelder, B. (2006). Towards the neurobiology of emotional body language. Nat. Rev. Neurosci. 7, 242-249. doi: 10.1038/nrn1872

Dehaene, S., Charles, L., King, J.-R., and Marti, S. (2014). Toward a computational theory of conscious processing. Curr. Opin. Neurobiol. 25C, 76-84. doi: 10.1016/j.conb.2013.12.005

Dehaene, S., and Naccache, L. (2001). Towards a cognitive neuroscience of consciousness: basic evidence and a workspace framework. Cognition 79, 1-37. doi: 10.1016/S0010-0277(00)00123-2

Delorme, A., and Makeig, S. (2004). EEGLAB: an open source toolbox for analysis of single-trial EEG dynamics including independent component analysis. J. Neurosci. Methods 134, 9-21. doi: 10.1016/j.jneumeth.2003.10.009

Di Dio, C., Di Cesare, G., Higuchi, S., Roberts, N., Vogt, S., and Rizzolatti, G. (2013). The neural correlates of velocity processing during the observation of a biological effector in the parietal and premotor cortex. Neuroimage 64, 425-436. doi: 10.1016/j.neuroimage.2012.09.026

Di Russo, F., Pitzalis, S., Aprile, T., Spitoni, G., Patria, F., Stella, A., et al. (2007). Spatiotemporal analysis of the cortical sources of the steady-state visual evoked potential. Hum. Brain Mapp. 28, 323-334. doi: 10.1002/hbm.20276

Downing, P. E., Jiang, Y., Shuman, M., and Kanwisher, N. (2001). A cortical area selective for visual processing of the human body. Science 293, 2470-2473. doi: $10.1126 /$ science. 1063414

Eckhorn, R., Bauer, R., Jordan, W., Brosch, M., Kruse, W., Munk, M., et al. (1988). Coherent oscillations: a mechanism of feature linking in the visual cortex? Multiple electrode and correlation analyses in the cat. Biol. Cybern. 60, 121-130. doi: 10.1007/BF00202899

Ekstrom, A. D., Caplan, J. B., Ho, E., Shattuck, K., Fried, I., and Kahana, M. J. (2005). Human hippocampal theta activity during virtual navigation. Hippocampus 15, 881-889. doi: 10.1002/hipo.20109

Engel, A. K., Roelfsema, P. R., Fries, P., Brecht, M., and Singer, W. (1997). Role of the temporal domain for response selection and perceptual binding. Cereb. Cortex 7, 571-582. doi: 10.1093/cercor/7.6.571

Feldman, H., and Friston, K. J. (2010). Attention, uncertainty, and free-energy. Front. Hum. Neurosci. 4:215. doi: 10.3389/fnhum.2010.00215

Flint, A. C., and Connors, B. W. (1996). Two types of network oscillations in neocortex mediated by distinct glutamate receptor subtypes and neuronal populations. J. Neurophysiol. 75, 951-957.

Frenkel-Toledo, S., Bentin, S., Perry, A., Liebermann, D. G., and Soroker, N. (2014). Mirror-neuron system recruitment by action observation: effects of focal brain damage on mu suppression. Neuroimage 87, 127-137. doi: 10.1016/j.neuroimage.2013.10.019

Friedman-Hill, S., Maldonado, P. E., and Gray, C. M. (2000). Dynamics of striate cortical activity in the alert macaque: I. Incidence and stimulus-dependence of gamma-band neuronal oscillations. Cereb. Cortex 10, 1105-1116. doi: $10.1093 /$ cercor/10.11.1105

Fries, P. (2005). A mechanism for cognitive dynamics: neuronal communication through neuronal coherence. Trends Cogn. Sci. 9, 474-480. doi: 10.1016/j.tics.2005.08.011 
Fries, P. (2009). Neuronal gamma-band synchronization as a fundamental process in cortical computation. Annu. Rev. Neurosci. 32, 209-224. doi: 10.1146/annurev.neuro.051508.135603

Fries, P., Neuenschwander, S., Engel, A. K., Goebel, R., and Singer, W. (2001a). Rapid feature selective neuronal synchronization through correlated latency shifting. Nat. Neurosci. 4, 194-200. doi: 10.1038/84032

Fries, P., Reynolds, J. H., Rorie, A. E., and Desimone, R. (2001b). Modulation of oscillatory neuronal synchronization by selective visual attention. Science 291, 1560-1563. doi: 10.1126/science. 1055465

Fries, P., Schröder, J.-H., Roelfsema, P. R., Singer, W., and Engel, A. K. (2002). Oscillatory neuronal synchronization in primary visual cortex as a correlate of stimulus selection. J. Neurosci. 22, 3739-3754.

Fries, P., Womelsdorf, T., Oostenveld, R., and Desimone, R. (2008). The effects of visual stimulation and selective visual attention on rhythmic neuronal synchronization in macaque area V4. J. Neurosci. 28, 4823-4835. doi: 10.1523/JNEUROSCI.4499-07.2008

Gevins, A., Smith, M. E., McEvoy, L., and Yu, D. (1997). High-resolution EEG mapping of cortical activation related to working memory: effects of task difficulty, type of processing, and practice. Cereb. Cortex 7, 374-385. doi: 10.1093/cercor/7.4.374

Giese, M. A., and Poggio, T. (2003). Neural mechanisms for the recognition of biological movements. Nat. Rev. Neurosci. 4, 179-192. doi: 10.1038/ nrn 1057

Girges, C., Wright, M. J., Spencer, J. V., and O'Brien, J. M. D. (2014). Eventrelated alpha suppression in response to facial motion. PLoS ONE 9:e89382. doi: 10.1371/journal.pone.0089382

Gramann, K., El Sharkawy, J., and Deubel, H. (2009). Eye-movements during navigation in a virtual tunnel. Int. J. Neurosci. 119, 1755-1778. doi: 10.1080/00207450903170361

Gray, C. M., König, P., Engel, A. K., and Singer, W. (1989). Oscillatory responses in cat visual cortex exhibit inter-columnar synchronization which reflects global stimulus properties. Nature 338, 334-337. doi: 10.1038/ $338334 \mathrm{a} 0$

Gruss, L. F., Wieser, M. J., Schweinberger, S., and Keil, A. (2012). Face-evoked steady-state visual potentials: effects of presentation rate and face inversion. Front. Hum. Neurosci. 6:316. doi: 10.3389/fnhum.2012.00316

Guitart-Masip, M., Barnes, G. R., Horner, A., Bauer, M., Dolan, R. J., and Duzel, E. (2013). Synchronization of medial temporal lobe and prefrontal rhythms in human decision making. J. Neurosci. 33, 442-451. doi: 10.1523/JNEUROSCI.2573-12.2013

Haegens, S., Osipova, D., Oostenveld, R., and Jensen, O. (2010). Somatosensory working memory performance in humans depends on both engagement and disengagement of regions in a distributed network. Hum. Brain Mapp. 31, 26-35. doi: 10.1002/hbm.20842

Heyes, C. (2010). Where do mirror neurons come from? Neurosci. Biobehav. Rev. 34, 575-583. doi: 10.1016/j.neubiorev.2009.11.007

Hirai, M., Fukushima, H., and Hiraki, K. (2003). An event-related potentials study of biological motion perception in humans. Neurosci. Lett. 344, 41-44. doi: 10.1016/S0304-3940(03)00413-0

Hirai, M., and Hiraki, K. (2006). The relative importance of spatial versus temporal structure in the perception of biological motion: an event-related potential study. Cognition 99, B15-B29. doi: 10.1016/j.cognition.2005.05.003

Hirai, M., Senju, A., Fukushima, H., and Hiraki, K. (2005). Active processing of biological motion perception: an ERP study. Brain Res. Cogn. Brain Res. 23, 387-396. doi: 10.1016/j.cogbrainres.2004.11.005

Hirai, M., Watanabe, S., Honda, Y., and Kakigi, R. (2009). Developmental changes in point-light walker processing during childhood and adolescence: an event-related potential study. Neuroscience 161, 311-325. doi: 10.1016/j.neuroscience.2009.03.026

Hirai, M., Watanabe, S., Honda, Y., and Kakigi, R. (2013). Developmental changes in point-light walker processing during childhood: a two-year follow-up ERP study. Dev. Cogn. Neurosci. 5, 51-62. doi: 10.1016/j.dcn.2013.01.002

Howard, M. W., Rizzuto, D. S., Caplan, J. B., Madsen, J. R., Lisman, J., Aschenbrenner-Scheibe, R., et al. (2003). Gamma oscillations correlate with working memory load in humans. Cereb. Cortex 13, 1369-1374. doi: 10.1093/cercor/bhg084

Ishihara, T., and Yoshi, N. (1972). Multivariate analytic study of EEG and mental activity in juvenile delinquents. Electroencephalogr. Clin. Neurophysiol. 33, 71-80. doi: 10.1016/0013-4694(72)90026-0
Jacob, P., and Jeannerod, M. (2005). The motor theory of social cognition: a critique. Trends Cogn. Sci. 9, 21-25. doi: 10.1016/j.tics.2004.11.003

Jeffreys, D. A. (1996). Simple methods of identifying the independently generated components of scalp-recorded responses evoked by stationary patterns. Exp. Brain Res. 111, 100-112. doi: 10.1007/BF00229559

Jensen, O., and Colgin, L. L. (2007). Cross-frequency coupling between neuronal oscillations. Trends Cogn. Sci. 11, 267-269. doi: 10.1016/j.tics.2007.05.003

Johansson, G. (1973). Visual perception of biological motion and a model for its analysis. Percept. Psychophys. 14, 201-211. doi: 10.3758/BF03212378

Jokisch, D., Daum, I., Suchan, B., and Troje, N. F. (2005). Structural encoding and recognition of biological motion: evidence from event-related potentials and source analysis. Behav. Brain Res. 157, 195-204. doi: 10.1016/j.bbr.2004.06.025

Kahana, M. J., Sekuler, R., Caplan, J. B., Kirschen, M., and Madsen, J. R. (1999). Human theta oscillations exhibit task dependence during virtual maze navigation. Nature 399, 781-784. doi: 10.1038/21645

Kandel, E. (2013). The new science of mind and the future of knowledge. Neuron 80, 546-560. doi: 10.1016/j.neuron.2013.10.039

Kang, J., Robinson, H. P. C., and Feng, J. (2010). Diversity of intrinsic frequency encoding patterns in rat cortical neurons-mechanisms and possible functions. PLoS ONE 5:e9608. doi: 10.1371/journal.pone.0009608

Keil, A., Gruber, T., Müller, M. M., Moratti, S., Stolarova, M., Bradley, M. M., et al. (2003). Early modulation of visual perception by emotional arousal: evidence from steady state visual evoked brain potentials. Cogn. Affect. Behav. Neurosci. 3, 195-206. doi: 10.3758/CABN.3.3.195

Kilner, J. M., Friston, K. J., and Frith, C. D. (2007). Predictive coding: an account of the mirror neuron system. Cogn. Process. 8, 159-166. doi: 10.1007/s10339-0070170-2

Klimesch, W. (1999). EEG alpha and theta oscillations reflect cognitive and memory performance: a review and analysis. Brain Res. Brain Res. Rev. 29, 169-195. doi: 10.1016/S0165-0173(98)00056-3

Klimesch, W. (2012). Alpha-band oscillations, attention, and controlled access to stored information. Trends Cogn. Sci. 16, 606-617. doi: 10.1016/j.tics.2012.10.007

Klimesch, W., Doppelmayr, M., Pachinger, T., and Russegger, H. (1997). Eventrelated desynchronization in the alpha band and the processing of semantic information. Brain Res. Cogn. Brain Res. 6, 83-94. doi: 10.1016/S09266410(97)00018-9

Klimesch, W., Doppelmayr, M., Schimke, H., and Pachinger, T. (1996). Alpha frequency, reaction time, and the speed of processing information. J. Clin. Neurophysiol. 13, 511-518.

Klimesch, W., Sauseng, P., and Gerloff, C. (2003). Enhancing cognitive performance with repetitive transcranial magnetic stimulation at human individual alpha frequency. Eur. J. Neurosci. 17, 1129-1133. doi: 10.1046/j.14609568.2003.02517.x

Klimesch, W., Sauseng, P., and Hanslmayr, S. (2007). EEG alpha oscillations: the inhibition-timing hypothesis. Brain Res. Rev. 53, 63-88. doi: 10.1016/j.brainresrev.2006.06.003

Klimesch, W., Schack, B., Schabus, M., Doppelmayr, M., Gruber, W., and Sauseng, P. (2004). Phase-locked alpha and theta oscillations generate the P1-N1 complex and are related to memory performance. Brain Res. Cogn. Brain Res. 19, 302-316. doi: 10.1016/j.cogbrainres.2003.11.016

Kocsis, B., Bragin, A., and Buzsáki, G. (1999). Interdependence of multiple theta generators in the hippocampus: a partial coherence analysis. J. Neurosci. 19, 6200-6212.

Krakowski, A. I., Ross, L. A., Snyder, A. C., Sehatpour, P., Kelly, S. P., and Foxe, J. J. (2011). The neurophysiology of human biological motion processing: a high-density electrical mapping study. Neuroimage 56, 373-383. doi: 10.1016/j.neuroimage.2011.01.058

Kravitz, D. J., Saleem, K. S., Baker, C. I., and Mishkin, M. (2011). A new neural framework for visuospatial processing. Nat. Rev. Neurosci. 12, 217-230. doi: $10.1038 / \mathrm{nrn} 3008$

Kruse, W., and Eckhorn, R. (1996). Inhibition of sustained gamma oscillations (35$80 \mathrm{~Hz}$ ) by fast transient responses in cat visual cortex. Proc. Natl. Acad. Sci. U.S.A. 93, 6112-6117. doi: 10.1073/pnas.93.12.6112

Leakey, M., and Walker, A. (1997). Early hominid fossils from Africa. Sci. Am. 276, 74-79. doi: 10.1038/scientificamerican0697-74

Leung, L. W., and Borst, J. G. (1987). Electrical activity of the cingulate cortex. I. Generating mechanisms and relations to behavior. Brain Res. 407, 68-80. doi: 10.1016/0006-8993(87)91220-0 
Liebe, S., Hoerzer, G. M., Logothetis, N. K., and Rainer, G. (2012). Theta coupling between V4 and prefrontal cortex predicts visual short-term memory performance. Nat. Neurosci. 15, 456-462, S1-S2. doi: 10.1038/nn.3038

Makeig, S., Westerfield, M., Jung, T. P., Enghoff, S., Townsend, J., Courchesne, E., et al. (2002). Dynamic brain sources of visual evoked responses. Science 295, 690-694. doi: 10.1126/science. 1066168

McAleer, P., Pollick, F. E., Love, S. A., Crabbe, F., and Zacks, J. M. (2014). The role of kinematics in cortical regions for continuous human motion perception. Cogn. Affect. Behav. Neurosci. 14, 307-318. doi: 10.3758/s13415-013-0192-4

McGlothlin, B., Jiacoletti, D., and Yandell, L. (2012). The inversion effect: biological motion and gender recognition. Psi Chi J. Psychol. Res. 17, 68-72.

McTeague, L. M., Shumen, J. R.,Wieser, M. J., Lang, P. J., and Keil, A. (2011). Social vision: sustained perceptual enhancement of affective facial cues in social anxiety. Neuroimage 54, 1615-1624. doi: 10.1016/j.neuroimage.2010. 08.080

Mitchell, D. J., McNaughton, N., Flanagan, D., and Kirk, I. J. (2008). Frontalmidline theta from the perspective of hippocampal "theta." Prog. Neurobiol. 86, 156-185. doi: 10.1016/j.pneurobio.2008.09.005

Mizuhara, H., Wang, L.-Q., Kobayashi, K., and Yamaguchi, Y. (2004). A long-range cortical network emerging with theta oscillation in a mental task. Neuroreport 15, 1233-1238. doi: 10.1097/01.wnr.0000126755.09715.b3

Müller, M. M., Teder-Salejarvi, W., and Hillyard, S. A. (1998). The time course of cortical facilitation during cued shifts of spatial attention. Nat. Neurosci. 1, 631-634. doi: 10.1038/2865

Müller, M. M., Teder, W., and Hillyard, S. A. (1997). Magnetoencephalographic recording of steady-state visual evoked cortical activity. Brain Topogr. 9, 163-168. doi: 10.1007/BF01190385

O'Keefe, J., and Recce, M. L. (1993). Phase relationship between hippocampal place units and the EEG theta rhythm. Hippocampus 3, 317-330.

Pavlova, M., Birbaumer, N., and Sokolov, A. (2006). Attentional modulation of cortical neuromagnetic gamma response to biological movement. Cereb. Cortex 16, 321-327. doi: 10.1093/cercor/bhi108

Pavlova, M., Lutzenberger, W., Sokolov, A., and Birbaumer, N. (2004). Dissociable cortical processing of recognizable and non-recognizable biological movement: analysing gamma MEG activity. Cereb. Cortex 14, 181-188. doi: 10.1093/cercor/bhg117

Pavlova, M., and Sokolov, A. (2000). Orientation specificity in biological motion perception. Percept. Psychophys. 62, 889-899. doi: 10.3758/BF03212075

Peyrin, C., Michel, C. M., Schwartz, S., Thut, G., Seghier, M., Landis, T., et al. (2010). The neural substrates and timing of top-down processes during coarseto-fine categorization of visual scenes: a combined fMRI and ERP study. J. Cogn. Neurosci. 22, 2768-2780. doi: 10.1162/jocn.2010.21424

Pinotsis, D. A., Brunet, N., Bastos, A., Bosman, C. A., Litvak, V., Fries, P., et al. (2014). Contrast gain control and horizontal interactions in V1: a DCM study. Neuroimage 92C, 143-155. doi: 10.1016/j.neuroimage.2014.01.047

Pollick, F. E., Kay, J. W., Heim, K., and Stringer, R. (2005). Gender recognition from point-light walkers. J. Exp. Psychol. Hum. Percept. Perform. 31, 1247-1265. doi: 10.1037/0096-1523.31.6.1247

Pozzo, T., Berthoz, A., and Lefort, L. (1990). Head stabilization during various locomotor tasks in humans. I. Normal subjects. Exp. Brain Res. 82, 97-106. doi: 10.1007/BF00230842

Press, C., Heyes, C., and Kilner, J. M. (2011). Learning to understand others' actions. Biol. Lett. 7, 457-460. doi: 10.1098/rsbl.2010.0850

Raghavachari, S., Kahana, M. J., Rizzuto, D. S., Caplan, J. B., Kirschen, M. P., Bourgeois, B., et al. (2001). Gating of human theta oscillations by a working memory task. J. Neurosci. 21, 3175-3183.

Raghavachari, S., Lisman, J. E., Tully, M., Madsen, J. R., Bromfield, E. B., and Kahana, M. J. (2006). Theta oscillations in human cortex during a workingmemory task: evidence for local generators. J. Neurophysiol. 95, 1630-1638. doi: 10.1152/jn.00409.2005

Ramalingam, N., McManus, J. N. J., Li, W., and Gilbert, C. D. (2013). Top-down modulation of lateral interactions in visual cortex. J. Neurosci. 33, 1773-1789. doi: 10.1523/JNEUROSCI.3825-12.2013

Ray, S., and Maunsell, J. H. R. (2010). Differences in gamma frequencies across visual cortex restrict their possible use in computation. Neuron 67, 885-896. doi: 10.1016/j.neuron.2010.08.004

Regan, D. (1966). Some characteristics of average steady-state and transient responses evoked by modulated light. Electroencephalogr. Clin. Neurophysiol. 20, 238-248. doi: 10.1016/0013-4694(66)90088-5
Rey, H. G., Fried, I., and Quian Quiroga, R. (2014). Timing of single-neuron and local field potential responses in the human medial temporal lobe. Curr. Biol. 24, 299-304. doi: 10.1016/j.cub.2013.12.004

Rizzolatti, G., and Craighero, L. (2004). The mirror-neuron system. Annu. Rev. Neurosci. 27, 169-192. doi: 10.1146/annurev.neuro.27.070203.144230

Rizzolatti, G., Fadiga, L., Gallese, V., and Fogassi, L. (1996). Premotor cortex and the recognition of motor actions. Brain Res. Cogn. Brain Res. 3, 131-141. doi: 10.1016/0926-6410(95)00038-0

Roberts, M. J., Lowet, E., Brunet, N. M., Ter Wal, M., Tiesinga, P., Fries, P., et al. (2013). Robust gamma coherence between macaque V1 and V2 by dynamic frequency matching. Neuron 78, 523-536. doi: 10.1016/j.neuron.2013. 03.003

Rojas, M., Masip, D., Todorov, A., and Vitria, J. (2011). Automatic prediction of facial trait judgments: appearance vs. structural models. PLoS ONE 6:e23323. doi: 10.1371/journal.pone.0023323

Rossion, B., Prieto, E. A., Boremanse, A., Kuefner, D., and Van Belle, G. (2012). A steady-state visual evoked potential approach to individual face perception: effect of inversion, contrast-reversal and temporal dynamics. Neuroimage 63, 1585-1600. doi: 10.1016/j.neuroimage.2012.08.033

Sadaghiani, S., Scheeringa, R., Lehongre, K., Morillon, B., Giraud, A.-L., D’Esposito, M., et al. (2012). $\alpha$-band phase synchrony is related to activity in the fronto-parietal adaptive control network. J. Neurosci. 32, 14305-14310. doi: 10.1523/JNEUROSCI.1358-12.2012

Sasaki, K., Gemba, H., Nambu, A., Kyuhou, S., Matsuzaki, R., and Tsujimoto, T. (1996a). Studies on integrative functions of the human frontal association cortex by use of MEG. Electroencephalogr. Clin. Neurophysiol. Suppl. 47, $181-190$.

Sasaki, K., Nambu, A., Tsujimoto, T., Matsuzaki, R., Kyuhou, S., and Gemba, H. (1996b). Studies on integrative functions of the human frontal association cortex with MEG. Brain Res. Cogn. Brain Res. 5, 165-174. doi: 10.1016/S09266410(96)00053-5

Sasaki, K., Tsujimoto, T., Nishikawa, S., Nishitani, N., and Ishihara, T. (1996c). Frontal mental theta wave recorded simultaneously with magnetoencephalography and electroencephalography. Neurosci. Res. 26, 79-81. doi: 10.1016/01680102(96)01082-6

Sauseng, P., Hoppe, J., Klimesch, W., Gerloff, C., and Hummel, F. C. (2007). Dissociation of sustained attention from central executive functions: local activity and interregional connectivity in the theta range. Eur. J. Neurosci. 25, 587-593. doi: 10.1111/j.1460-9568.2006.05286.x

Saygin, A. P., Wilson, S. M., Hagler, D. J. Jr., Bates, E., and Sereno, M. I. (2004). Point-light biological motion perception activates human premotor cortex. J. Neurosci. 24, 6181-6188. doi: 10.1523/JNEUROSCI.050404.2004

Sceniak, M. P., Hawken, M. J., and Shapley, R. (2002). Contrast-dependent changes in spatial frequency tuning of macaque V1 neurons: effects of a changing receptive field size. J. Neurophysiol. 88, 1363-1373.

Schütz-Bosbach, S., and Prinz, W. (2007). Perceptual resonance: actioninduced modulation of perception. Trends Cogn. Sci. 11, 349-355. doi: 10.1016/j.tics.2007.06.005

Sederberg, P. B., Kahana, M. J., Howard, M. W., Donner, E. J., and Madsen, J. R. (2003). Theta and gamma oscillations during encoding predict subsequent recall. J. Neurosci. 23, 10809-10814.

Silva, L. R., Amitai, Y., and Connors, B. W. (1991). Intrinsic oscillations of neocortex generated by layer 5 pyramidal neurons. Science 251, 432-435. doi: $10.1126 /$ science. 1824881

Singer, W. (1999). Neuronal synchrony: a versatile code for the definition of relations? Neuron 24, 49-65, 111-125. doi: 10.1016/S0896-6273(00) 80821-1

Singer, W. (2009). Distributed processing and temporal codes in neuronal networks. Cogn. Neurodyn. 3, 189-196. doi: 10.1007/s11571-009-9087-z

Tallon-Baudry, C., and Bertrand, O. (1999). Oscillatory gamma activity in humans and its role in object representation. Trends Cogn. Sci. 3, 151-162. doi: 10.1016/S1364-6613(99)01299-1

Tallon-Baudry, C., Bertrand, O., Delpuech, C., and Pernier, J. (1996). Stimulus specificity of phase-locked and non-phase-locked $40 \mathrm{~Hz}$ visual responses in human. J. Neurosci. 16, 4240-4249.

Thorpe, S. K. S., Holder, R. L., and Crompton, R. H. (2007). Origin of human bipedalism as an adaptation for locomotion on flexible branches. Science 316, 1328-1331. doi: 10.1126/science.1140799 
Traub, R. D., Cunningham, M. O., Gloveli, T., LeBeau, F. E. N., Bibbig, A., Buhl, E. H., et al. (2003). GABA-enhanced collective behavior in neuronal axons underlies persistent gamma-frequency oscillations. Proc. Natl. Acad. Sci. U.S.A. 100, 11047-11052. doi: 10.1073/pnas.1934854100

Traub, R. D., Jefferys, J. G., and Whittington, M. A. (1997). Simulation of gamma rhythms in networks of interneurons and pyramidal cells. J. Comput. Neurosci. 4, 141-150. doi: 10.1023/A:1008839312043

Troje, N. F., Westhoff, C., and Lavrov, M. (2005). Person identification from biological motion: effects of structural and kinematic cues. Percept. Psychophys. 67, 667-675. doi: 10.3758/BF03193523

Ulloa, E. R., and Pineda, J. A. (2007). Recognition of point-light biological motion: mu rhythms and mirror neuron activity. Behav. Brain Res. 183, 188-194. doi: 10.1016/j.bbr.2007.06.007

Urgen, B. A., Plank, M., Ishiguro, H., Poizner, H., and Saygin, A. P. (2013). EEG theta and $\mathrm{Mu}$ oscillations during perception of human and robot actions. Front. Neurorobotics 7:19. doi: 10.3389/fnbot.2013.00019

Vaina, L. M., Solomon, J., Chowdhury, S., Sinha, P., and Belliveau, J. W. (2001). Functional neuroanatomy of biological motion perception in humans. Proc. Natl. Acad. Sci. U.S.A. 98, 11656-11661. doi: 10.1073/pnas.191 374198

Vidal, J. R., Perrone-Bertolotti, M., Levy, J., De Palma, L., Minotti, L., Kahane, P., et al. (2014). Neural repetition suppression in ventral occipito-temporal cortex occurs during conscious and unconscious processing of frequent stimuli. Neuroimage 95C, 129-135. doi: 10.1016/j.neuroimage.2014.03.049

Viviani, P., and Stucchi, N. (1992). Biological movements look uniform: evidence of motor-perceptual interactions. J. Exp. Psychol. Hum. Percept. Perform. 18, 603-623. doi: 10.1037/0096-1523.18.3.603

Walter, W. G., and Dovey, V. J. (1944). Electro-encephalography in cases of sub-cortical tumour. J. Neurol. Neurosurg. Psychiatry 7, 57-65. doi: 10.1136/jnnp.7.3-4.57
White, N. C., Fawcett, J. M., and Newman, A. J. (2014). Electrophysiological markers of biological motion and human form recognition. Neuroimage 84, 854-867. doi: 10.1016/j.neuroimage.2013.09.026

Whittington, M. A., and Traub, R. D. (2003). Interneuron diversity series: inhibitory interneurons and network oscillations in vitro. Trends Neurosci. 26, 676-682. doi: 10.1016/j.tins.2003.09.016

Zanto, T. P., Rubens, M. T., Thangavel, A., and Gazzaley, A. (2011). Causal role of the prefrontal cortex in top-down modulation of visual processing and working memory. Nat. Neurosci. 14, 656-661. doi: 10.1038/nn.2773

Zeki, S., Watson, J. D., Lueck, C. J., Friston, K. J., Kennard, C., and Frackowiak, R. S. (1991). A direct demonstration of functional specialization in human visual cortex. J. Neurosci. 11, 641-649.

Conflict of Interest Statement: The authors declare that the research was conducted in the absence of any commercial or financial relationships that could be construed as a potential conflict of interest.

Received: 30 May 2014; accepted: 31 August 2014; published online: 18 September 2014.

Citation: Zarka D, Cevallos C, Petieau M, Hoellinger T, Dan B and Cheron G (2014) Neural rhythmic symphony of human walking observation: Upside-down and Uncoordinated condition on cortical theta, alpha, beta and gamma oscillations. Front. Syst. Neurosci. 8:169. doi: 10.3389/fnsys.2014.00169

This article was submitted to the journal Frontiers in Systems Neuroscience.

Copyright (c) 2014 Zarka, Cevallos, Petieau, Hoellinger, Dan and Cheron. This is an open-access article distributed under the terms of the Creative Commons Attribution License (CC BY). The use, distribution or reproduction in other forums is permitted, provided the original author(s) or licensor are credited and that the original publication in this journal is cited, in accordance with accepted academic practice. No use, distribution or reproduction is permitted which does not comply with these terms. 